\title{
Clay Objects as 'Tokens'? Evidence for Early Counting and Administration at Late Neolithic Tell Sabi Abyad, Mesopotamia
}

\author{
Tell Sabi Abyad was a major Neolithic settlement in upper Mesopotamia, \\ occupied for 1,800 years during the $7^{\text {th }}$ to $6^{\text {th }}$ millennium BC. Excavations have \\ revealed hundreds of clay sealings, stamp-seal impressions and an even greater \\ number of small, geometric-shaped clay objects or 'tokens'. Drawing on previous \\ unpublished data from decades of excavations, a detailed, contextual study of the \\ form and distribution of Tell Sabi Abyad's 'tokens' is presented. Though likely \\ used as counting tools in certain specific occupational areas and levels, the \\ evidence does not suggest a singular universal role of geometric clay objects as \\ mnemonic accounting devices.
}

Keywords: Neolithic; token; Near East; sealing; Mesopotamia

\section{Introduction}

Small, geometrically shaped clay objects initially appear at a limited number of early agricultural villages across Mesopotamia and the wider Near East towards the start of the Neolithic period, the mid-10 $10^{\text {th }}$ millennium BC; at Sheikh-e Abad, Mureybet, Jericho, and Çayönü for example (Broman Morales 1990; Kenyon \& Holland 1983: 356, 815, fig. 367.6; Matthews et al. 2013: 140, 141, 142, tbl. 11.5). By the late Neolithic $\left(7^{\text {th }}\right.$ and $6^{\text {th }}$ millennium BC), clay objects are present in abundance at a large number of sites across the region, being particularly characteristic of so-called Halaf settlements (sites dating to the $6^{\text {th }}$ millennium BC of upper Mesopotamia). However they remain absent at other sites (including Ebaba, Jani, Musular, Pınarbaşı, Shir, Wadi Shu'eib) (BennisonChapman 2014).

The non-functional term 'clay object' is used throughout this article to refer specifically to the small geometric-shaped artefacts of clay, more commonly labelled as 'tokens' in academic literature (other artefacts of clay will be referred to by their 
common name: stamp-seal, figurine, sealing etc.). The appearance of clay objects (Fig. 1) in the archaeological record of the Neolithic period in the Near East coincides with the onset and development of fundamental economic, social and technological innovations including most importantly, the emergence of the world's first sedentary agricultural villages (see for example Childe 1936; Redman 1977; Verhoeven 2011; Watkins 2010). The significance of clay objects to these early farming communities is suggested by both the timing of their appearance, and their enduring nature. Clay objects persist into the $1^{\text {st }}$ millennium $\mathrm{BC}$ in the region, where they were used alongside written records and sealings as administrative aids. However the bulk of functional analysis of these objects has focused on the later, historic-period clay objects (post midlate $4^{\text {th }}$ millennium BC), with the initial 'tokens' of the Neolithic period largely assumed to also have had administrative origins (Schmandt-Besserat 1992a; 1992b; 1996). Detailed, large scale studies of clay objects, potentially Neolithic 'tokens', combining contextuality and materiality are almost entirely absent at present. This research attempts to address this problem.

The well-known late Neolithic site of Tell Sabi Abyad, upper Mesopotamia is used to investigate the role and function of the earliest clay objects. Excavations have revealed hundreds of clay sealings, stamp-seal impressions and an even greater number of small, geometric-shaped clay objects. With its 1,800 year occupation, broad horizontal exposures and diverse material culture, Sabi Abyad is the ideal site to investigate questions related to the presence, distribution, contextual deposition and thus the use, meaning and evolution of clay objects within the Neolithic of the Near East. Incorporating spatial data, this site-based analysis focuses on object form, quantities and the level of diversity evidenced in both spheres within and across different phases, levels and discrete areas of settlement. Research questions include: what are the 
defining characteristics of clay objects as an artefact category? How homogeneous are the objects in terms of appearance, manufacture, use and deposition? Are distinct artefact 'sets' found within discrete village settlements? Is a temporal evolution in clay object form and complexity of function evidenced? Where on site where they used and disposed of? What with and by whom? Are clay objects commonly or exclusively used and disposed of alongside seals and/or sealings, thus supporting the administrative role ascribed to their proto and historic period counterparts? Is there any evidence to suggest a singular, uniform and consistent function of clay objects at Sabi Abyad? Their use within the sphere of administration will not be assumed, rather evidence supporting a range of possible functions will be considered. This includes the potential use of clay objects in administration (as simple counting or more complex, information storage devices), as well as functions such as toys, gaming pieces and ritual use.

\section{Research context}

The presence of large numbers of small geometric clay objects at sites across the Near East has long been acknowledged. It was not until clay bullae, hollow spherical clay envelopes, marked with seal impressions on the outside and containing small clay objects (Fig. 2), were first excavated, dating to the proto and early historic periods (late $4^{\text {th }}-2^{\text {nd }}$ millennium BC) that attention focused for the first time on the small clay objects themselves. The earliest publication of clay objects comes from archaeologist J. de Morgan et al. (1905). He produced a catalogue of artefacts including items labelled as 'tokens', 'counters' and 'bullae'. Leo Oppenheim (1959) and Amiet (1966) were crucial in linking clay objects to counting and administration, cementing the link between clay objects, bullae and sealing practices in the early historic period of south Mesopotamia (Amiet 1966; Leo Oppenheim 1959). 
From the advent of writing in the mid- late $4^{\text {th }}$ millennium BC, it is generally agreed that geometric clay objects were used alongside early administrative texts, clay seals, sealings, and bullae (Fig. 2), functioning as accounting 'tokens'. As part of a complex mnemonic recording system, their shape, size and decorative elaboration symbolically identified them as representing a set unit of a specific commodity. However, scholars focusing on the origins of cuneiform script and administration in the Near East's early state societies admit that exactly how this system operated, the symbolic value of clay objects, and the relationship between seals, sealings, tokens, bullae and early administrative texts is still not fully understood (Leo Oppenheim 1959; Nissen et al. 1993: 11-13, fig. 113 p. 130, fig. 3 p. 5; Robinson 2007: 60-61, 62-62; Sampson 1985: 57-61; Schmandt-Besserat 1992a: 7, 108-110, 129-130; 1996: 7, 102). The first study of Neolithic clay objects concerned Jarmo's late Neolithic $\left(6^{\text {th }}\right.$ millennium) artefacts, completed by Broman in 1958 (also Broman Morales 1990). However since then, it is the late $4^{\text {th }}$ and $3^{\text {rd }}$ millennium BC clay objects and associated texts, bullae and sealings that have been the focus of interest, with their prehistoric counterparts largely ignored. Denise Schmandt-Besserat bought the topic of prehistoric clay objects to the fore in her research into their function from the Neolithic into the $3^{\text {rd }}$ millennium BC (Schmandt-Besserat 1978a; 1978b; 1979; 1981; 1982; 1992a; 1992b; 1996). Cementing the perceived link between clay objects and administrative practices, Schmandt-Besserat claims that from their inception (thought to be in the 8th millennium BC), clay objects functioned as mnemonic, administrative 'tokens' (1992a, 1996). Clay objects, she argues, formed the basis of agricultural administration. They were part of a system which operated in an identical way across all villages of the ancient Near East, from the Neolithic period into the late fourth millennium BC. Evidence to support Schmandt-Besserat's theory is however, based almost solely on clay objects from proto- 
and early historic period south Mesopotamia, far removed from the period and place in which they initially emerge (Schmandt-Besserat 1992b). Furthermore, SchmandtBesserat assesses clay objects on appearance alone, ignoring their immediate context and the nature of the site at which they were recovered. Thus she presents no solid, convincing evidence to support the claim that during the Neolithic period, clay objects were invented to be used as administrative, recording 'tokens' and that this function remained unchanged until the invention of writing in the late 4th millennium (Schmandt-Besserat: 1992a, 1992b, 1996). Though opposition has been voiced (Brown 1996; Damerow 1993; Englund 1993; 1998; Friberg 1994; Michalowski 1993), Schmandt-Besserat's interpretation dominates academic thought on the role of Neolithic clay objects, which are commonly termed 'token' in Neolithic site reports with little or no explanation of this functional label (e.g. Çilingiroğlu et al. 2004: p. 48, fig. 31 p. 125; Cole et al. 2013; Eslick \& Voigt 2017: 88-91; Forouzan et al. 2012; Nashli \& Moghimi 2013; Richardson 2014; Özbal et. al. 2004: fig. 13 p. 104, fig. 15 p. 106). Aside from the inferred administrative function of clay objects in the Neolithic period, the interpretation of small, geometric shaped clay objects as gaming pieces is the main alternative argument posited for Neolithic and later Near Eastern objects. Yet the motivation for this interpretation is seldom explained. The term 'gaming piece' is often found in site reports, presumably based on analogies of modern and historic board games, rather than the context of clay objects within the site, the presence of playing boards or other possible gaming related artefacts (for example at Jarmo: Broman Morales 1983: 386; Jericho: Kenyon \& Holland 1982: fig. 266.1-5, p. 557-58; Kenyon \& Holland 1983: fig. 367.6 (reg. no. 2886) p. 816; Sabi Abyad: Verhoeven \& Akkermans 2000: 108, fig. 4.7.4, p. 117). 


\section{Terminology \& Classification}

There is no universal definition of what exactly constitutes a 'token' in the Near East, archaeologically speaking. Schmandt-Besserat defines tokens as small, geometric clay objects. Yet her catalogue (1992b) also incorporates figurines (animal representations), and non-geometric (pictographic and naturalistic) items including miniature vessels as well as stone artefacts. Costello, in her study of 'symbol use' and 'external memory storage', uses the French term 'jeton' rather than 'token' (2002, 2011). Costello's 'tokens' are clearly defined, and her categorisation is clear and distinct from Schmandt-Besserat's. 'Jetons' are discs of two basic materials: 'sherds' and 'stone' (Costello 2002: 45). All are disc-shaped. 'Sherd discs' are chipped and shaped pottery sherds (Costello 2000: 246, fig. 1 p. 475; Costello 2002: iv, 55). 'Stone discs' are either artefacts shaped from stone or naturally occurring, non-modified river pebbles (Costello 2002: 55-56). The jetons range from 2-13 cm diameter (Costello 2002: 56).

Other multi-site studies on 'tokens' are rare. Due to the uncertain function of small geometric clay objects, especially in prehistoric contexts, the term token is often used (with little or only a vague discussion of its meaning) interchangeably with other terms, including 'jeton', 'gaming piece', 'counter', 'cone', 'ball', 'disc', 'geometric', 'clay object', 'tally', 'stamp', 'miscellaneous...', 'small object for ritual purposes' and 'figurine' in site-reports and excavation catalogues (see for example Broman Morales 1990: p. 22, 23-24, 25, 35 (Sarab); Duru \& Umurtak 2005: pl.130.1/pl.171.1 (Höyücek); Mahasneh \& Gebel 1998: table 2 p. 107 (Es-Sifiya); Tekin 2007: 51, fig. 14 (Hakemi Use); Small Finds 2010; Voigt 1983: p. 184-85 (Haji Firuz Tepe)). Issues of artefact categorisation, terminology and functional uncertainty have led to alike objects being recorded under different classifications, even within a single site. What one 
archaeologist may interpret as a 'schematic figurine', another might record as a 'cone', 'token', 'shaped-clay' or 'miscellaneous clay artefact' (for example at Jericho, geometric clay objects are recorded under: 'miscellaneous clay objects and vessels' in Kenyon \& Holland 1983: 559 and as 'Gaming Pieces' in Kenyon \& Holland 1982: 557 amongst other terms).

\section{Late Neolithic Tell Sabi Abyad}

Tell Sabi Abyad, north Syria (Fig. 3) was excavated by Peter Akkermans 1985 to 2010 (Akkermans 1989a; 1989b; 1991; 1993; 1996a; 1996b; Akkermans \& Duistermaat 1996; Akkermans \& Verhoeven 1995; Akkermans et al. 2006; 2010; 2012; 2014; Nieuwenhuyse et al. 2010; Verhoeven 1999; Verhoeven \& Akkermans 2000). Excavations have yielded huge numbers of small finds. The site's excavation strategy led to the meticulous excavation of internal areas, resulting in the recovery of a number of discrete assemblages of finds from within buildings, including geometric clay objects, clay sealings (including many impressed with stamp-seal impressions), figurines and pottery.

Neolithic Sabi Abyad was occupied for approximately 1,800 years, from the mid- $8^{\text {th }}$ millennium into the first half of the $6^{\text {th }}$ millennium BC. Culturally, this equates to the Pre-Pottery Neolithic B (henceforth PPNB) into the Middle Halaf period (Fig. 4) (Akkermans et al. 2014: 27-28, tbl. 1.3 p. 28; Verhoeven \& Akkermans 2000: 1). The site is actually four tells aligned in a linear pattern south to north, named Tells Sabi Abyad I-IV (Fig. 3) (Akkermans et al. 2014: fig. 1.5 p. 19; Nieuwenhuyse et al. 2010: fig. 3 p. 76). As a whole, Sabi Abyad was never simultaneously occupied; settlement shifted from tell to tell, and across different parts ('operations') of the largest mound, Tell Sabi Abyad I (Figs 4 \& 5). 
Mound Sabi Abyad II is the location of the site's earliest occupation, settled in the mid- $8^{\text {th }}$ millennium during the PPNB (Verhoeven \& Akkermans 2000). Sabi Abyad III was settled soon after (Figs 3 and 4) (Akkermans et al. 2006; Nieuwenhuyse et al. 2010: 74-76). The earliest occupation of Tell Sabi Abyad I (Fig. 5) is found at operation III, at the start of the Initial Pottery Neolithic (henceforth Initial PN) c. 7,000-6,800 BC (Fig. 4). By the mid- $7^{\text {th }}$ millennium BC, the entire western half of Tell Sabi Abyad I was occupied (operations II, IV and V), co-existing with continued settlement at Sabi Abyad II and III (Figs 4 \& 5) (Akkermans et al. 2006; Akkermans et al. 2012). Settlement on tells Sabi Abyad II and III then declines, disappearing altogether by the end of the Early Pottery Neolithic c. 6,300 BC. Tell Sabi Abyad I remains occupied into the Middle to Late Halaf periods (Fig. 4) (Akkermans et al. 2006).

\section{Operation I, Tell Sabi Abyad I}

Excavations at operation I, in the southeastern part of the main tell have revealed a continuous series of short-lived villages dated to $6,200-5,850 \mathrm{BC}$, the Pre-Halaf to the end of the Early Halaf cultural phases (Akkermans et al. 2014: 29, 32, tbl. 1.3 p. 28, tbl. 2.2 p. 31) (Fig. 4 \& 5). Spanning a total of 350 years, each village has an average life span of 35 years (Akkermans et al. 2014: 32, 32-86, tbl. 2.2 p. 31). The exceptionally preserved, 'Burnt Village' of level 6 (c. 6,010-5,995 BC) represents arguably the most well-known example of Neolithic administrative activity to date. The village yielded hundreds of clay sealings within room-fill, and occasionally in situ (Akkermans \& Duistermaat 1996; Akkermans \& Verhoeven 1995: 8-9, 12-13, 15, 21-25; Akkermans et al. 2014: 67-78; Duistermaat 1996; Duistermaat \& Schneider 1998; Verhoeven 1999: esp. 203-32). An extensive fire ripped through much of the level 6 village. This intentional, ritual destruction incorporated the in-filling of specific rooms alongside mortuary activity (Akkermans pers. comm., Oct 2015; Akkermans \& Duistermaat 1996: 
17; Akkermans et al. 2014: 31-32, 68, 77, fig. 2.29 p. 69; Nieuwenhuyse pers. comm., Oct 2015; Verhoeven 1999). Two infant burials were recovered from burnt structures. Ritual activity is further hinted at by the presence of eleven large clay, hollow ovoidshaped sculptures, seemingly representing animals (Akkermans \& Verhoeven 1995: 12, 13, 16, fig. 7 p. 16, fig. 8 p. 17). Originally placed on the roof of building V, before the fire began, these stylised 'animals' were recovered alongside the crushed and burnt remains of two adults.

\section{Operation II, Tell Sabi Abyad I}

To the north of the Burnt Village lies operation II (Fig. 5). The $10 \times 10 \mathrm{~m}^{2}$ space is dominated by a large T-shaped building during both of its occupation phases (Akkermans et al. 2012: fig. 3 p. 311; 2006: fig. 3 p. 130). The lower phase (levels 4-3) T-shaped building was set alight at the end of its life c. 6,050-6,020 BC (just decades prior to the burning of operation I's level 6 village), in a controlled and deliberate act (Akkermans et al. 2012: 309-12, fig. 3 p. 311, fig. 5 p. 312). In its scale, preservation, internal division of space and deliberate destruction, this building is reminiscent of the rectilinear structures of operation I's Burnt Village. Before being set alight, the body of a young woman was placed on the floor of the northeastern room (Room 8) (Akkermans et al. 2012: 312-14, fig. 6 p. 313). Devoid of any features or artefacts, Room 8 acted solely as a burial chamber. Raging at high temperatures and causing extensive damage, the fire did not affect Room 8 or the burial inside it (Rooms 1, 2, 3 and 5 are heavily burnt, Rooms 6 and 7 are partially burnt), demonstrating the fire was a deliberate, managed, seemingly ritual act (Akkermans et al. 2012: 310-12, 314, 321).

The burning of the lower T-shaped building was accompanied by the deposition of hundreds of (mostly broken) artefacts including pottery, groundstone tools, clay figurines and 'tokens' (Akkermans et al. 2012: 314-18, fig. 7 p. 314, fig. 8 p. 315 , tbl. 2 
p. 315). Almost all of the buildings' rooms were full deep with ash; cultural materials were present in the upper halves of room-fill (Akkermans et al. 2012: 317, 318, 321-22, fig. 4 p. 312). The deposition of items was highly structured, finds of certain categories cluster in specific rooms (Akkermans et al. 2012: 318-21, fig. 10 p. 319, tbl. 2 p. 315, tbl. 3 p. 317). A few decades later, the T-shaped structure was rebuilt, to the same alignment and plan, a few metres north of the original building (Akkermans pers. comm., Oct 2015; Akkermans et al. 2006: 129, fig. 3 p. 130, 131, tbl. 2 p. 128). Though less than $50 \%$ of the building was exposed during excavation, the T-shaped building of the upper (levels 2-1) occupational phase of operation II shares many similarities to the original structure. Room 2, a small $1.25 \times 1.25 \mathrm{~m}^{2}$ space is heavily burnt throughout, including all layers of the $>1.00 \mathrm{~m}$ deep ashy room-fill (Akkermans et al. 2006: 129). Room 2 alone contained $>300$ clay objects, most from the upper fill (Akkermans pers. comm., Oct 2015).

\section{Tell Sabi Abyad's geometric clay objects}

\section{Categorisation}

The term clay object is used in this paper to describe the small artefacts more commonly known as 'tokens'. The nature of archaeology is that boundaries between artefact categories can be blurred. A cone-shaped artefact of clay may be interpreted as a gaming piece by on person, a labret by another, and a schematic human form, thus registered as a figurine by third. For this study therefore, previously used designations and sub-categories (as published or used in excavation databases and site records) across all clay artefact types were disregarded. A detailed identification and selection strategy was drawn up in order to retrieve and record only those objects that may have functioned together as artefacts and as possible, early administrative tools. In order to 
keep the study focused the definition of a 'clay object' was intentionally kept tight in scope (definition below). The presence and relative location of other artefacts of clay (e.g. sealings, figurines) were taken into account when interpreting clay objects and their context, yet these artefacts were not part of the core study assemblage.

Clay objects are (1) small (generally $<5 \mathrm{~cm}$ maximum dimension), (2) intentionally crafted artefacts, (3) shaped into a geometric form (sphere, cube, cone). They can be plain or decorated with markings (impressions or incisions). Comparable objects of plaster are included within this definition. Stone objects are included only when they are similar in size, shape and elaboration to comparable objects of clay. Natural, unshaped, non-geometric pebbles are excluded from the study. So too are reused pot sherds (table 1).

'Clay artefact' is used to refer to all archaeological finds made from clay. The broad term includes the common archaeological categories of 'figurine', 'sealing', 'sling-missile' and 'pot-sherd disc' (table 1). Likewise clay artefacts of a distinct and certain function, that might also be geometric in shape, such as clay stamp-seals, clay beads, clay labrets and pottery (including miniature forms) are not included within the classification of clay object (table 1).

\section{Materials and methods}

Small, geometric-shaped clay objects as defined above, are the most common artefact at Sabi Abyad, after pottery and lithics. A filtered search of the Sabi Abyad finds database returns over 1,535 records fitting the definition (table 2). Each refers to either a single or group of objects (objects registered as 'tokens' or other related), therefore, the actual number of recovered clay objects from Sabi Abyad is certainly much higher than 1,535. A comparatively small number of clay objects from Sabi Abyad have previously been individually studied and published, with the clay objects 
individually illustrated or described in any detail relating only to the projects earliest excavation seasons (Akkermans 1996b: $n=55$ individually illustrated clay objects from a total count of 197, pp. 441-43, 456-57; Akkermans \& Verhoeven 1995: $n=31$ 'tokens' illustrated, fig. 14.1-31, p. 24; Verhoeven 1999: $n=182$ 'tokens' from operation I, level 6 listed (1986-1993 excavation seasons, none illustrated or individually described; Verhoeven \& Akkermans 2000: 5 illustrated: fig. 4.7.4-6 p. 117, fig. 4.12.8-13 p. 121, fig. 4.13.9, p. 122, from a total of 19 listed, 91-92, 102, 105, tbl. 4.2 p. 92).

To date, clay artefact interpretations at Sabi Abyad have focused on the operation of seals and sealings, and the role 'tokens' had within this context (i.e. Akkermans \& Duistermaat 1996; Duistermaat 1996; Duistermaat \& Schneider 1998), especially those recovered from the level 6 village of operation I (c. 6,010-5,995 BC) excavated during the projects early years. Large numbers of 'tokens' continued to be excavated in later seasons, including outside of operation I, yet until now these have remained largely unpublished, with detailed, functional studies entirely absent (in relation to 'tokens' from operation I's 1994-1999 seasons see Akkermans et al. 2014: 44, tbl. 7.9 p. 172; for counts of 'tokens' recovered in operation II's 2004 season see Akkermans et al. 2012: 316, tbl. 2 p. 315; for operation II 2002-03 seasons see Akkermans et al. 2006: 129, 131, 132). This paper addresses the lack of a thorough and comprehensive study of Sabi Abyad's clay objects, amalgamating artefact data from a number of sources, covering the entire span of excavation seasons, excavation areas and occupational phases. These are divided into three sample groups: tiers 1,2 and 3, according to the differing levels of data available for each object (Fig. 6). 


\section{Datasets: Tier 1}

293 clay objects were studied individually, in person, on site in Syria during the 2010 season, forming the tier 1 dataset. Examined in the greatest detail, for each tier 1 object, a multitude of variables covering appearance, manufacture, post depositional treatment and find context (tell, operation, phase, level, nature and detail of immediate context) were recorded. All clay objects excavated during the 2010 field season (Sabi Abyad III) were recorded, as well as an arbitrary selection of clay objects from previous seasons. The aim was to return to site in 2011 and 2012 in order to expand the study sample, however due to the political situation in the region, work on-site was abruptly terminated.

\section{Tier 2}

In order to increase the sample number, all individually illustrated and/or described, published objects fitting the research criteria were studied individually, in as much detail as possible, supplementing the published information with additional details (such as object dimensions and detailed contextual information) from unpublished site archives. This sample forms the tier 2 dataset and totals 100 artefacts; 96 published and 4 objects studied from unpublished documentation alone (Fig. 6). As with the tier 1 assemblage, each tier 2 object was individually studied and recorded. Yet the methodology necessitated that not as much detailed information could be gathered for individual tier 2 objects as all were studied from documentation only (none were viewed in person). The overall count of individually studied clay objects (tiers 1 and 2 combined) totals 393. These objects form the basis of the discussion below. 


\section{Tier 3}

The individually studied objects from Sabi Abyad (tiers 1 and 2) are the focus of this paper, however, in order to study and assess the function of clay objects within the wider context of Sabi Abyad, across its multiple mounds, settlements and millennia of occupation, an estimated total clay object count was obtained from the projects finds database, totalling 1, 535 tier 3 objects (table 2). This figure can be filtered to give an estimated clay object total according to specific excavation season, tell/mound and operation (settlement area within the main tell). References in publications, to total counts of 'tokens' within specific locations and levels or phases within them (table 3) were also used to study clay objects (of tier 1 or 2) of discrete locations (tell, operation/area of the main tell, and stratigraphic level) within their wider context.

\section{A typology of 'tokens'}

Tell Sabi Abyad's clay objects are diverse in shape. They can be grouped into seven basic and 16 detailed three-dimensional shapes (Fig. 7, table 4). Cone for example, is a diverse category, represented by 4 sub-types (Fig. 7, table 4). The tier 1 and 2 assemblages are equally as diverse in shape. Both assemblages are dominated by spheres (as a broad category) in identical proportions (38\%, Fig. 7). In all other aspects, the proportion of specific, detailed three-dimensional shapes differs across tiers 1 and 2 (Fig. 7).

All clay objects are small, almost all with a $\leq 5 \mathrm{~cm}$ maximum dimension (Fig. 8). Within specific three-dimensional shapes, a graduated range of sizes is apparent. There is no evidence for sets of 'small' as opposed to 'large' cones or spheres for example (Fig. 9). With size distinctions having the potential to convey meaning such as quantity, this is a notable absence. Likewise, within specific three-dimensional shape categories, variation is evidenced within length, width and height ratios. As a result, objects of the 
same shape classification present can have a different overall look (Fig. 10 \& 11). The vast majority $(71 \%)$ of clay objects weigh between $1-10 \mathrm{~g}$. Weight differences can be seen across the different shape categories (Fig. 12). Yet such differences are negligible as average weight values across the different three-dimensional shape categories are broadly similar and in appearance, sets of large (heavy) and small (light) objects are absent (Fig. 12).

Various types of clay were used to manufacture the clay objects. The use of stone to create comparable artefacts (classified under the term 'clay object' for the purposes of this study) is rare (7 examples), with gypsum/rock crystal (CO\# 2879) and limestone (CO\#s 2913 and 2914) most common. A range of simple techniques were used to initially shape the objects, utilising the hands and a flat surface. The common presence of fingerprints and fingernail impressions evidence human manipulation of the objects. A smaller number $(n=43,15 \%)$ of tier 1 objects appear to have been applied to a flat or contoured surface during manufacture (Fig. 13). Almost all studied (tier 1 and 2) clay objects display a 'fine' clay texture with a 'smooth' or 'very smooth' outer surface. This results in the simply made artefacts having an accomplished finish (table 5). Almost all of the tier 1 sample appear to have been intentionally hardened in some way (lightly baked or sun-dried, 89\%). Close inspection shows the objects are solid, durable yet not burnt (just 5\%) or cracked due to heat exposure. For the small proportion of clay objects with burning on the outer surface, this appears to be postdepositional (see context discussion below).

The surface texture and finish of Sabi Abyad's clay objects shows high levels of similarity to clay objects from pre-ceramic Neolithic Boncuklu Höyük (Konya Plain, Turkey). Here the majority of clay objects are unburnt, recovered from non-burnt contexts and survive the archaeological flotation process, demonstrating they were 
intentionally hardened in some way. Likewise, experimental work on the site's clay objects has shown the placement of wet clay objects in the summer sun for just a few hours' results in a solid object, with the appearance of having been fired. Placement at the edge of a hearth or open fire produces similar results (Baird 2016: 18).

A relatively high proportion of Sabi Abyad's (tier 1) clay objects display elaboration in the form of intentional, decorative markings, 38\% (Fig. 14, tables 4 \& 6). Markings have the potential to distinguish decorated objects from their plain counterparts and therefore the potential to convey meaning through difference (as seen in later, historic period 'complex tokens'. Schmandt-Besserat 1992a: 36, 37, 49; Woods 2010: fig 2.15 p. 48, no. 23-27 pp. 62-63). The proportion of marked objects varies considerably across different three-dimensional shape categories, suggesting that within some shapes, decoration could have been used as an additional distinguishing feature (table 4).

\section{Rare examples}

A number of Sabi Abyad's clay objects stand out from the wider assemblage due to the presence of unique features. Remarkable for their high level of craft, less common and extremely well-defined three-dimensional shape, are the four stone examples. Their dimensions, along with their shape raises the possibility that they performed the same role to that of their clay counterparts, being used alongside them as part of a group of alike artefacts (Fig. 15). Unique for a number of reasons is cylinder CO\# 2911 (one of just 6 cylinders identified). At $8.70 \mathrm{~cm}$ in length, it is almost twice as long as other cylindrical examples, and the only cylinder in stone (Fig. 14). Its uniqueness of form suggests a unique function. Another notable tier 2 object is the 'game piece? Token' (CO\# 2912). The face is covered in deep rounded depressions. Its decoration shares similarities with CO\# 226 (Fig. 14). 
Two further objects are noteworthy due to the impressions found on them. CO\# 287 displays an intricate design on its base surface (Fig. 16). The relative thickness of the object, along with the two opposing, shallow, finger-tip sized depressions on the object's upper, surface suggest that this clay object may have in-fact operated as a clay stamp-seal. Similarly distinctive is CO\# 105, a disc baked from a fine, mid-brown coloured clay (Fig. 17). Both its top and base surfaces display a design covering almost the entire face. The impression (clear and deep at $0.15 \mathrm{~cm}$ ) appears to be the result of a stamp-seal yet CO\# 105 is not a sealing in the traditional sense. As an object it remains complete and intact. Its shape, along with the lack of the impressions of string or a container are evidence against it having been used to secure an item. Where were clay objects used?

\section{Temporal distribution}

Clay objects occur throughout the temporal span of Neolithic Sabi Abyad, from the mid-to late eight into the $6^{\text {th }}$ millennium BC (Fig. 4, tables $3 \&$ 7,). Little clear temporal patterning is evidenced across the broad span of occupation with fluctuations across each phase of settlement. One single phase, the Transitional Halaf $(6,020-5,925$ BC) contains almost half of all (fully phased) studied clay objects (table 7). The broad temporal fluctuations are likely due to specific details of contextual deposition of clay objects (see below). There is no significant difference in the nature of clay objects nor a development in form or diversity through time at Sabi Abyad. The relative number of the four most common shapes for example, remains constant when comparing objects of the broad Late Neolithic occupation (c. 6,900-5,700 BC) to the Transitional phase (c. $6,020-5,925 \mathrm{BC}$ ) within it. 


\section{Area of site}

Clay objects appear across all tells, areas and phases of occupation at Sabi Abyad, yet they are unevenly distributed. Clay objects are particularly rare in the earliest areas to be settled. Late PPNB and Early Ceramic Neolithic Sabi Abyad III for example have uncovered just 18 clay objects (across all three study tiers). Just 19 clay objects (tiers 1 to 3) were recovered from contemporary Sabi Abyad II (table 3). With such low numbers of clay objects found across the initial phases of settlement, it seems likely the use of clay objects was restricted in distribution to just one or two households or group(s) of people. In this context, it seems unlikely that clay objects were used to perform any major community role or task essential to day-to-day life on Tells II or III, nor pre $6,300 \mathrm{BC}$.

The broad temporal and spatial distribution of clay objects shows huge disparities across the various discrete village settlements of Tell Sabi Abyad I. These cannot be equated to duration of settlement nor size of exposure. The villages of operations I and III for example are comparably sized and dense in architecture (Fig. 5). The duration of occupation at operation III was at least twice as long as at operation I (Fig. 4), yet the two areas have proportionate clay object counts (table 8). Operations II and IV share similarities in all aspects aside from their quantities of clay objects (table $8)$.

\section{Temporal distribution by area}

\section{Operation III}

Operation III is the longest occupied zone at Tell Sabi Abyad I. Much of the area is dominated by a large cemetery in the final phase of its use (c. 6,000 BC onwards). Clay objects are only found in substantial quantities in the earliest half of the 
sequence (the 'A' series of stratigraphic levels, Fig. 4), the Initial and Early Pottery Neolithic phases of the $7^{\text {th }}$ millennium BC; 85\% $(n=46)$ of the III's tier 1 assemblage, rising to $96 \%$ of the tier 3 data set (Fig. 18). Looking in closer detail at the exact settlement level within operation III only, significant numbers of clay objects are found across five sequential levels; levels A4-B8, the end of the Early PN into the Pre-Halaf periods (c. 6,400-6,125 BC) (Figs 4 \& 18). This is reflected by density analysis, which shows clay objects peak in two periods at operation III, levels A4-B8 and level A12 c. 6,790 BC, the start of the Early Pottery Neolithic period (Figs 4 \& 18). Therefore, although present at the operation III village from early on, clay objects only appear in substantial numbers from level A4, being an integral part of village life at operation III in the last quarter of the $7^{\text {th }}$ millennium BC only. After this point, they dramatically decline in number. During the same period, ceramic analysis attests to the adaptation of pottery for storage purposes. This is evidenced by an increase in pottery vessel densities along with an increase in container volume. Since clay objects are possible administrative tools, the co-timing of these two characteristics suggests they may be linked (Nieuwenhuyse 2018).

\section{Operation II}

The small, short lived village settlement represented by operation II (Tell Sabi Abyad I) is particularly dense in clay objects. Similar features characterise its upper and lower settlement phases, yet more than three quarters of operation II's clay objects ( $78 \%, n=383$ ) come from the upper sequence c. $6,000-5,800 \mathrm{BC}$ (the late Transitional/ Early Halaf period). This is despite the fact that the building dominating the village at this time was only partially exposed. Separated merely by decades, the more than fourfold increase in clay objects from operation II's lower to upper sequences suggests the during the lower settlement phase, clay objects were used and developed as a tool 
(table 9). During the upper settlement phase, the large increase in clay object quantities suggests their role and associated activities became more important in operation II. If clay objects were used for counting for example, during the upper sequence, counts utilising clay objects likely became more frequent, complex (involving larger numbers and/or greater variety of commodities/subjects), leading to people becoming reliant on clay objects to perform their increasingly complex counting tasks

\section{Operation I}

Operation I demonstrates an even starker uneven temporal distribution of clay objects. Wide-exposure excavations characterise a series of continuous village settlements across eight levels spanning the late Pre-Halaf, Transitional and Early Halaf phases (Fig. 4). Clay objects cluster almost exclusively in the middle of the sequence. The Transitional Halaf (c. 5,925-6,020), contains $84 \%$ of all of all tier 1 and 2 objects ( $n$ =72) (Fig. 19, table 10). The tier 3 data supports this patterning, with almost all (182 of the 197) published clay objects from operation I also coming from the Transitional phase (Akkermans 1996b: tbl. 8.1 p. 442, 441-43; Verhoeven 1999). The same is true of the unpublished tier 3 data.

Operation I's Transitional Halaf phase is represented by four distinct village levels (4-7), yet it is level 6, the Burnt Village which contains the vast majority of clay objects across all three tiers of recording (tables $3 \& 11$ ). The exceptional archaeological preservation seen in level 6 partially explains the high proportion of clay objects here in comparison to other levels. Excavation techniques also play a factor; the level 6 village was exposed to a far greater degree than the preceding or following levels. Yet even taking these aspects into account, level 6 has a disproportionately high number of clay objects within operation I. The temporal distribution of operation I's clay objects suggests they were only universally used over three to five generations, 
from the establishment of the large level 6 village c. 6,125-6,175 until its destruction c. 6,010-5,995 BC. With occupation within each level of operation I relatively short lived at (a maximum average life span of 35 years per level. Akkermans et al. 2014: 32), the use of clay objects in this area of Sabi Abyad I was an extremely short lived phenomenon.

\section{Detail of deposition}

The overwhelming majority, 74\%of clay objects from Sabi Abyad's tier 1 and 2 assemblage are recovered from the umbrella category of 'fill', in contrast to $8 \%$ from 'structural' context types. Fill objects are found in a diverse array of contexts including 'hearth fill' (9\%), 'pit fill' (10\%) and 'room-fill' (11\%) (Fig. 20). It is notable that burnt and ashy fills contain some of the highest proportions of clay objects ( $21 \%$ of 'fill' context clay objects), especially when, as noted above, a negligible proportion of clay objects appear burnt. The recovery of largely unburnt clay objects from ashy fills demonstrates they were intentionally hardened during manufacture processes (baked or lightly fired, leaving no trace of blackening on their surface), used, and finally disposed of in ashy fills. Variability in the proportion of clay objects from the different basic fill types can be seen across different areas of the site. 56\% of Sabi Abyad tell III's objects come from 'grave/burial fill'. In contrast, despite its large cemetery zone, $<1 \%$ of Tell Sabi Abyad I's operation III's clay objects come from grave/burial fill.

Regardless of whether clay objects come from fill or structural contexts, almost two thirds come from a context located in an open-air or external area, 65\% $(n=254)$ (table 12). At first glance, the abundance of clay objects in external areas would be evidence against their predominant interpretation as recording devices. It is often imagined that administrative clay objects were archived after use, stored inside buildings as a record of transaction, as seen in the later proto and early historic period of 
south Mesopotamia. However in the Neolithic setting, this is not necessarily the case. Clay objects might have been used in open air spaces, to count animals or goods as they arrived into the village from surrounding areas. The long-term archival of clay objects inside buildings is an additional, non-essential component of a basic administrative function.

Examination of the detailed nature of the internal or external clay object yielding areas is more informative regarding object function. The 254 external area clay objects come from locations including 'courtyard', 'open area', 'passage' 'pit' and 'midden' (table 12). Yet rather than being found placed in specific depositions or features representing possible archival activity (a pit within a courtyard for example), the overwhelming majority of external area clay objects come from basic 'open area' locations (with no further recorded features) $(n=175$, table 12). Almost all external area clay objects appear to have been simply tossed away once their purpose had been served. Among the 121 clay objects found within 'internal' areas, all come from buildings, recovered from in a range of locations within them including 'oven', 'wall', 'under room floor' and 'doorway' (table 12). Yet the vast majority come from broad 'room' context types, 113 clay objects (93\% of internal space objects). The concentration of clay objects inside rooms, rather than in locations representative of their incidental presence (doorway or wall for example) is intriguing. Yet 'room' contexts almost always represent room-fill, rather than in situ depositions. Only one or two clay objects were recovered from the surface of a room floor, thus representative of a primary deposit (table 12).

There is significant variation in the relative proportions of clay objects from broad external compared to internal areas across different operations and areas of Sabi Abyad, along with differences in the nature of those contexts. This indicates clay 
objects functioned differently in different areas of the site. At Tell Sabi Abyad I, 87\% of operation I's clay objects come from internal area contexts. Operation III displays the reverse patterning (Fig. 21). These differences cannot be explained by differences in excavation practices, nor in the nature of the site at either location. There appears to be a real difference in the disposal and therefore, use of clay objects across different areas.

\section{Operation I}

Across the level 6 village's buildings and the rooms inside them, clay objects were deposited within specific rooms of certain buildings only. Tholoi (curvilinear structures) contain very low proportions of clay objects, with just five clay objects recovered from only two different tholoi. Rectilinear buildings contain the majority of the village's clay obejcts, $76 \%(n=45)$ come from a single building, Building II. Within this building, 40 of the 45 clay objects come from Room 6 alone.

\section{Operation II}

In addition to the main study data set, further research utilising data from unpublished site archives reveals that operation II's settlement shares many remarkable similarities to that of operation I's Burnt Village. Operation II's upper and lower settlement phases are both dense in clay objects. A total of 489 were recovered from this relatively small, $100 \mathrm{~m}^{2}$ area, almost exclusively from internal spaces (Fig. 21). Clay objects were almost entirely recovered from room-fill, alongside hundreds of pottery sherds and large numbers of other artefacts of clay including figurines, sealings, pot sherd discs and remnants of four possible bullae (CO\#s 2915-18).

As seen at the Burnt Village, the deposition of clay objects is highly structured at operation II. The burnt, lower sequence T-shaped building contains a total of 90 'tokens', all from room-fill. Almost half were recovered from a single room, the heavily 
burnt Room $3(n=42)$. The remainder are distributed across a further three rooms (table 13). A co-occurrence of clay objects alongside sealings, pottery sherds and pot-sherd discs is clear within this building, with the four artefact type's common within the same limited range of burnt rooms (table 13). Only four rooms of the upper sequence Tshaped building have been revealed, yet in layout and artefact distribution, the building shares many similarities to its predecessor (Fig. 22). Almost all clay objects of the upper sequence come from inside the T-shaped building, $86 \%$ of them from Room 2 alone.

\section{'Tokens' in clusters}

A substantial proportion, $38 \%$ of studied clay objects (with information available) were recovered with at least one other artefact (of any type) in direct association $(n=132)$. When a clay objects is found with just one other artefact, the additional artefact is most often a second clay object (as opposed to a figurine, pot sherd etc.). Clay objects are more commonly recovered as part of a 'cluster' $(n=105)$, defined as a clay object recovered alongside two or more additional artefacts (clay object or other). 'Clusters' are interpreted as primary depositions with a high level of certainty. Likewise, 'cluster' clay objects commonly have at least one additional clay object as part of their cluster ( $n=41,39 \%$ of cluster objects). Clusters vary in size from groups of three to four alike clay objects, to caches of 'many hundreds' of artefacts, including two or three clay objects or many tens or even hundreds of clay objects. Half of all clusters studied $(n=52)$, are large, comprising artefact counts of 100 or more.

The geographic and temporal distribution of 'cluster' clay objects, the nature and number of the associated finds all add to our understanding of clay object use and disposal. All come from the largest tell, Tell Sabi Abyad I, meaning temporally, no preceramic Neolithic clusters are found. The earliest clusters date to the second half of the $7^{\text {th }}$ millennium BC and are found in operation III's level A4. Proportionally, early 
cluster objects are rare, $15 \%(n=41)$ of operation III's studied objects. In contrast, $100 \%$ of studied objects from operation II (dating to the later part of the occupational sequence) are cluster objects. At operation II, the use of clay objects was exclusively linked to their use in groups alongside other clay objects in addition to other artefacts of clay. All come from the T-shaped buildings' which dominate both occupational phases of operation II.

Overall, the majority of cluster objects $(57 \%, n=60)$ come from operation I. All of operation I's cluster objects come from a single occupation level, level 6-the Burnt Village (c. 6,010-5,995 BC), representing 90\% of the Burnt Village's clay object total. Like operation II, the dominance of cluster objects within level 6, operation I suggests a specific method of clay object use or disposal during a short temporal window. Similarities in the architecture and use of space between operations I and II at this time support this theory. Both operation I and II c. 6,000 exhibit buildings with rooms full of clay objects and other clay finds along with evidence of intentional burning and other ritual activities. Cluster clay objects (across all site areas and occupational phases) come from distinct contexts. In contrast to the overall patterning, $70 \%$ of cluster objects hail from internal areas $(n=73)$, predominantly from room-fill. The distribution of cluster objects is not limited to buildings of a particular architectural style (Fig. 23 top). Yet when relative percentages of all studied objects and cluster objects according to detailed contextual distribution are compared, it is clear that cluster objects disproportionally come from inside rectilinear buildings (Fig. 23 bottom).

The appearance of clusters in the mid- $7^{\text {th }}$ millennium after a millennia of nonclustered use is intriguing, and is likely linked to many of the other cultural changes that impacted on later $7^{\text {th }}$ millennium BC societies in the region (Nieuwenhuyse $\&$ Akkermans forthcoming; Nieuwenhuyse et al. 2010). Cluster clay objects are recovered 
almost solely with other artefacts made of clay, including other clay objects, sealings (plain and stamped), figurines, sling-missiles and pot-sherd discs. Sealings do not appear at Sabi Abyad in any substantial number, until over one millennia after the appearance of the site's first clay objects. A few possible examples of sealings can be found in operation III, with the earliest definitive examples of clay sealings dating to the very end of the $7^{\text {th }}$ millennium $\mathrm{BC}$, from operation I levels 8 and $7 \mathrm{a}$. Soon after, sealings appear in huge quantities with more than 300 recovered from level 6 of operation I alone. Operation I's level 6 Burnt Village shows an indisputable co-association of sealings and clay objects. Room 6 of Building II for example, was found full of artefacts. Aside from many geometric clay objects, more than 150 clay sealings were recovered, in addition to ceramics, stone bowls, axes, bone tools, labrets, clay figurines and (Akkermans 1996b: 441; Akkermans \& Verhoeven 1995: 12-13). Building V contained similarly large assemblages of sealings and clay objects in Rooms 6 and 7 (Akkermans 1996b: 441; Akkermans \& Verhoeven 1995: 13, 15).

Within operation II's upper sequence T-shaped burnt building, a number of clusters consisting of clay objects and other artefacts of clay were identified. The heavily burnt Room 2 contained $99 \%$ of the building's clay objects. They were not randomly distributed throughout the fill, but recovered from distinct clusters within it, representing discrete deposition acts. Room 2's lower fill contained a group of eight clay objects alongside eight other varied artefacts of clay. The middle fill contained a single cluster of 135 clay objects and 4 additional artefacts made from clay. The uppermost fill layer contained a number of smaller clusters, each representing artefact depositions of 3 to 29 clay objects, totalling 187 individual artefacts. 
Clay object morphology by context: operation I

Level 6 (which contains the majority of operation I's clay objects, $n=67$, all from internal areas), is the only level to display the full range of three-dimensional shapes, dominated by spheres and 'other' shaped objects. Differences can be seen in the contextual deposition of clay objects according to shape. Just two of level 6's (tier 1) clay objects come from an open area, both are cones (Fig. 24). Clay objects from tholoi are limited to two shapes, spheres and cones, whereas rectilinear buildings contain (tier 1) clay objects of all shapes (Fig. 24). This hints at meaning being held within a clay object's three-dimensional shape.

\section{Summary}

Clay objects accumulate in significant numbers within certain phases of select village settlements only. Within these locations, clay objects are concentrated in distinctive contexts. Rare in pre-ceramic phases, clay objects are most dense in Tell Sabi Abyad's operations I and II, where they are most commonly recovered in clusters, from internal spaces, most often room-fill of rectilinear or T-shaped buildings. This points to a distinct, and similar functioning of clay objects at the end of the $7^{\text {th }}$ into the start of the $6^{\text {th }}$ millennium BC, in conjunction with the appearance of sealing use. Yet this patterning is not universal across all occupied areas of the site. The peculiar contextual patterning evidenced does not appear to be accidental, nor able to be explained away by preservation issues. In part, the high proportion of clay objects recovered from room-fill as opposed to external areas can be attributed to excavation methods. Yet when analysing clay object distributions within a single occupational horizon, stark differences in the density of clay objects from one room or building to another cannot be overlooked. 


\section{Discussion}

Sabi Abyad's clay objects are well crafted, into a well-defined range of geometric shapes. A significant proportion display intentional decoration, fingerprints and fingernail impressions, meaning these items cannot be dismissed as mere lumps of clay, accidents of preservation. Clay objects are found right across the expanse of tells which make up the site, covering a temporal span of almost two millennia. Their appearance (size, range of shapes, proportion decorated and form of decoration) shows no temporal or geographical change.

Relatively rare during the pre-ceramic period, high densities and numbers of clay objects occur at Sabi Abyad in three discrete locations only. The earliest appearance of clay objects in substantial numbers occurs relatively late in the sequence at Tell Sabi Abyad I's operation II levels A4-B8 (c. 6,400-6,125 BC (Fig. 18, table 9). Clay objects are notably absent at contemporary areas of operations IV and V at this time. Clay objects fall out of favour during the Pre-Halaf phase, until the very end of the $7^{\text {th }}$ millennium BC, when they increase substantially, dominating the material culture record of operation I and II villages (tables $2,9 \& 10$ ). Clay objects continue to occur throughout the rest of the Halaf period at Tell Sabi Abyad I, though on a much reduced scale. This decline, along with the lack of temporal or spatial patterning in the type of clay objects recovered from discrete village phases, suggests that in opposition to Schmandt-Besserat's (1992a, 1996) theory, no overarching increase in the use/disposal and range of clay objects is seen during Sabi Abyad's almost 2,000 year occupation.

Consideration of artefact deposition is crucial to the assessment of artefact use in the past. One important aspect to note is that clay objects are generally recovered discarded in the contexts we find them. Overall, they are generally recovered singly, from open-air general/ashy fill layers (Fig. 20, table 12). This represents the care-free 
disposal of individual objects once they have fulfilled their use-life. Clay objects might have been single-use, disposed of immediately afterwards. Yet they could have been used and re-used multiple times before finally being disposed of. Therefore, a simplistic discard rate $=$ use rate scenario may not be accurate. Likewise, stark differences in disposal are seen across different areas. Large quantities of clay objects only ever occur in exposures dominated by dense architecture, yet notably not in all such instances (lacking across most levels of operation III, and operation I levels 7A, 5A/B, 4 and 3). In such settings, clay objects are rarely recovered as single finds. Temporally all exposures with significantly high numbers of clay objects come from a single discrete time-frame at the very end of the $7^{\text {th }}$ into the start of the $6^{\text {th }}$ millennium BC.

Operation I's Burnt Village (6,010-5,995 BC) and both the lower (c. 6,0506,020 BC) and upper (c. 6,000-5,800 BC) sequences of operation II all contain high numbers of clay objects, recovered from clusters inside buildings. This represents all occupied zones c. $6,000 \mathrm{BC}$ (operation III was used almost exclusively as a cemetery area from the Pre-Halaf period onwards), suggesting that at this point in time, the majority of villagers across Tell Sabi Abyad I were engaging in a specific activity requiring, clay objects more than ever before. Clay objects were crucial elements of an activity characteristic of Neolithic village life c. 6,000 BC.

Clay objects are often found alongside or in the same broad contexts as sealings. It is no coincidence the use of sealings surges at Sabi Abyad, and across upper Mesopotamia at the same time as 'token' use. The lower sequence T-shaped building of operation II contains at least 76 sealings, distributed across three rooms, all of which also contain significant quantities of clay objects (table 13). Operation I's Burnt Village is well known for its large number of sealings (312), $63 \%$ of which are impressed with 
unique impressions of no less than 77 unique stamp-seals (Akkermans \& Duistermaat 2004: 2; Duistermaat 1996; Akkermans \& Duistermaat 1996; Verhoeven 1999).

The introduction of sealing practices in the late Neolithic suggests concepts of personal ownership, resource control and organisation were strong elements within Near Eastern village societies. Tell Sabi Abyad is no exception. In both operation II and level 6 operation I, clay objects are recovered alongside not only sealings but other artefacts of clay including pot-sherd discs (lids), figurines and pottery (suggesting storage) (Akkermans \& Verhoeven 1995; Akkermans et al. 2012) (table 13). This places clay objects at the location of secured, storage. All evidence combined suggests that certain rooms within the T-shaped buildings of operation II were used to store goods and other items related to storage and the administration of stored goods. The same conclusion is reached upon assessment of the distribution of clay objects and other clay finds across rooms within the buildings of operation I's level 6 village (Akkermans \& Duistermaat 1996; Akkermans \& Verhoeven 1995; Duistermaat 1996; Spoor \& Collet 1996; Verhoeven 1999). In all three areas therefore clay objects were very likely used in the sphere of administration, in activities linked to secured and stored goods c. 6,000 BC.

\section{Neolithic Administration}

The similarities in structured deposition of clay objects and other clay artefacts, within buildings, across operation I level 6 and operation II are stark. As is evidence for the burning and abandonment of the structures. Within a very limited time-frame of two to three generations, groups of villagers across different parts of Tell Sabi Abyad I were using clay objects in a very similar fashion. Utilised alongside sealings, clay objects, were at this point in time, an essential and widespread part of material culture. The evidence points to their functioning as administrative tools. Whilst this may, at first 
glance, validate the hypothesis put forward by Schmandt-Besserat (1992a, 1992b, 1996), we have to consider administration in what form?

\section{Counting}

There are many options for the use of simple clay objects in accounting activities in the Neolithic Near East. The simplest function is counting and clay objects could have been useful counting aids. One-to-one counting with clay objects would serve to increase the accuracy of counts, prevent people from losing count and allow for simple calculations of addition and subtraction. The use of clay objects in counting could be particularly useful when need to keeping track of quantity related to things or events over an extended time period, counting in a busy or chaotic environment or when the result of various counts needed to be combined into one. Counting using clay objects would enable high numbers to be reached without the need for numeracy skills. If, as the absence of abstract number in the earliest written records of south Mesopotamia for the first 1,000 years of writing (until the end of the $3^{\text {rd }}$ millennium $\mathrm{BC})$, can be taken as evidence of the lack of a concept of abstract number until this point in time, abstract counting would have been difficult without a counting aid (Brown 1996: 39; Englund 1993: 1671; Friberg 1994: 482, 483; Michalowski 1993: 998; Nissen at al.: 134-38). The use of clay objects as counters would be advantageous as the resultant pile of clay objects would represent the number of days, sheep, portions of grain etc. which had been accounted for. The larger the pile, the larger the quantity of the count, thus an immediate and easily understandable visual aid would be created by the use of clay objects. Upon a glace, quantities from different counts could be compared. 


\section{Information storage-numerical data}

Sets of clay objects could be retained, acting as a record of number, linked to the specific counting activity they had performed. The set of clay objects could be recounted, and checked; useful if for examples, goods, people or animals were to be moved from one place to another (between storerooms, owner(s), or localities). In this system, the clay objects held no mnemonic or symbolic value. Yet, the system could be enhanced if clay objects of a certain shape were, on an ad-hoc basis, used to simultaneously count two or more different variables (e.g. sheep and cows, or lentils and nuts). The administrator would then use the shape to remember which set of objects related to which set of goods and whilst they were retained, they would act as a record of number.

\section{Complex calculations and information storage}

Simple, small objects are capable of being used to process, compute and retain complex information as commonly evidenced ethnographically. The position of clay objects (or other items) on a board or abacus enables the assignment of different values to individual pieces, which can then be used to calculate number, and whilst they remain in position, to retain those numerical values (as seen in Classical Greece in the use of the Western Abacus, Netz 2002). Simple, alike small objects can be used to gather and retain complex, information of a numerical and non-numerical nature.

Officials in the West African Kingdom of Dahomey (c. AD 1600-1900) used a system of pebbles, baskets and symbols to gather and retain detailed census records (Herskovits 1932). Births, deaths, age and sex according to village, town and province were all recorded, stored and updated. Archives consisted of rooms full of large boxes. Births for a particular region for example would be housed in the room related to that region. The 'birth-box' would be subdivided into two rows of smaller boxes; one row for males and 
another for females. Each column of two boxes (male and female) represented a year, thus at the end of the year, all pebbles in the first column representing new-borns, were moved across one row, into the section representing 1 year olds. The rows continued year by year, up to fourteen years, allowing new births for the following year to be placed into the new-born boxes by sex. After the fourteenth year, the pebbles were transferred into the adult boxes, one for males and another for females. If a person died, a pebble would be removed from the box representing their age and sex at death, and then moved into a separate room recording death, being placed into a box or sack according to their region, age, sex and manner of death (Herskovits 1932: 258). When records were gathered annually for presentation to the king, different symbols on the exterior of the boxes and baskets represented the various demographics by region (Herskovits 1932: 255, 55, 60).

The examples above demonstrate the potential capacity of clay objects in the Neolithic context. Sabi Abyad and other Neolithic sites in the Near East have clay objects in a variety of shapes. This prompts the question as to why people would take the extra time and effort to create objects of diverse appearance, if the appearance inconsequential? Perhaps clay objects were shaped and decorated purely for aesthetic purposes? They were after all, quickly and easily made. More likely, the differing characteristics of clay objects could have been ways to distinguish counts of one item from another, or counts of the belongings of one person/household from those of another owner. With shape the only clear and consistent variable within the Sabi Abyad assemblage, this feature could have provided the ability to simultaneously count and/or retain multiple numerical sets of data side by side. 


\section{Motivation and need}

The need for complex societies to have a systematic administrative system is obvious, yet in the context of a small, farming village, what might have been administered? By who and for what purpose? Early agricultural communities certainly would have had the need to count many things. People, livestock, agricultural produce, processed foods and raw materials. The Neolithic was a time of increasing diversification of labour and specialisms, external exchange and craft-production. Therefore it is likely villagers would have had the need to assess productivity, output, stored goods and raw materials: the number of tools made per day, the units of grain processed per day or the number of portions of meat resulting from a butchery event for example. In addition, it is likely farmers would have had the need to keep track (via counting) of days, months and longer periods of time, for agricultural reasons, along with religious, ritual and other purposes.

From the onset of the Neolithic period, food storage is evidenced in the Near East (i.e. at Wadi Faynan 16 and Drah'. Finlayson, Kuijt et al. 2011: 129-30; Finlayson, Mithen, Najjar et al. 2011: 8182-8186; Kuijt 2011: 138). The late Neolithic was a time of increasing private ownership and storage, clearly evidenced at Sabi Abyad (and other Halaf sites; Kuijt 2011: 137-38), especially at operation I (level 6) and II c. 6,000 BC. Farmers likely accounted for what was stored, removed from storage, distributed and redistributed, at least at the most basic level of counting out allocations of a commodity.

\section{Who were the administrators?}

A controversial interpretation of the Sabi Abyad's level 6 Burnt Village was first posited by the excavation team (Akkermans \& Duistermaat 1996; expanded upon by Verhoeven 1999). The theory interprets the village layout, combination of architectural styles, the presence and distribution of sealings, and the corresponding lack of actual 
stamp-seals as evidence of the existence of a dual society comprised of permanent 'residents' and temporary 'nomads' (Akkermans \& Duistermaat 1996; Verhoeven 1999). The nomads, it is argued, used the village as a centre for storage and exchange. Storerooms housed their goods, which were sealed and administered using 'tokens', miniature vessels and figurines (representing goods, services and/or animals) (Akkermans \& Duistermaat 1996: 19).

This interpretation has many unexplained assumptions (see for example comments in Akkermans \& Duistermaat 1996: 33-41), and has since been revised. Crucially, artefacts (sealings, 'tokens', figurines etc.) within rooms were in most cases, not recovered in situ, and do not represent archival activity, but the disposal of artefacts during or post-building abandonment. Therefore, though clay objects were likely used in the same context in which stored commodities were processed (counted, allocated or redistributed), there is no evidence clay objects were retained as archives inside buildings. This is not to say sets of clay objects were not stored alongside the stored commodities in their original setting. Secondly, there is no evidence for the existence of nomads, yet nor is there evidence of social hierarchy. Sixty-seven individual stamp-seal designs are present at the level 6 village, yet they might not have been contemporary. The sixty-seven designs can be reduced to twenty-seven actual basic designs (goat, parallel chevrons, leaping gazelle etc.), with additional variation found in stamp-seal impression size, shape or other more minor details. The total number of seals, and according seal holders, at any one time, would have been much lower than originally presented (by Akkermans \& Duistermaat 1996; Verhoeven 1999). The size of the level 6 village, number and capacity of its buildings, duration of occupation and estimated population size would allow for at least each household and at most, each adult to own an induvial seal. Thus seal owners, and therefore those involved in administration 
activities utilising stored goods and clay objects would have been at least one person from each household, possibly every able, adult member of the community. This would allow them to take an active role in the administration of their property.

\section{Ritual links and alternative uses}

At both operation I level 6 and operation II's lower sequence, ritual action accompanies the disposal of clay objects. Perhaps the disposal of clay artefacts was part of an end-of use-life ritual associated with burial, abandonment and burning. Prehistoric sites of the Near East commonly evidence the ritual destruction or 'killing' of artefacts once their primary role has been exhausted (intentional pottery breakage and burial, intentional figurine breakage and 'stabbing' e.g.: Merpert \& Munchaev 1987: 26, 27; Oates 1978: 119; Rollefson 1986: pl. II.4, 50; Verhoeven 2007). Overall, the level of diversity seen across all aspects of clay object form, temporal distribution and contextual deposition is evidence against a singular, consistent and universal function of clay objects at Sabi Abyad and across the wider Near East. The basic nature of clay objects likely allowed them to fulfil various functions. Some objects, the unique and particularly highly-crafted examples (Figs $14 \& 15$ ) likely had a unique function. Aside from ritual use, gaming is the alternative function most likely served by clay objects. Though no boards have been found at Sabi Abyad, at least thirteen potential gaming boards of limestone and plaster, complete with rows of hollow depressions, have been excavated across the Neolithic Near East in recent years (Bartl pers. comm., April 2012; Finlayson, Mithen, Najjar et al. 2011: 8183; Simmons \& Najjar 2006: 88, fig 7 p. 88; Simpson 2007: 5-8). Boards could have been marked out on the ground, or games played without the use of a board making the interpretation of some clay objects as gaming pieces at Sabi Abyad a realistic option. 


\section{Wider context}

Tell Sabi Abyad is just one of a large number of Neolithic Near Eastern sites and cannot be understood in isolation. This is especially true if as commonly proposed, clay objects were utilised as part of an inter-site system of mnemonic-aided administration. Sites across the Neolithic Near East are united by a number of shared characteristics, yet there is also considerable diversity. Clay objects have a wide temporal and geographic distribution across the entire zone (Bennison-Chapman 2014: ch. 10). Clay objects are common at most, yet not all Neolithic Near Eastern sites, and little patterning is evidenced according to the presence, relative number of clay objects, type of object and site nature.

The exception is the late Neolithic of upper Mesopotamia c. 6,000 BC onwards. Clay objects are typical features of these of sites. It is interesting to note that temporally, the major trends apparent at Sabi Abyad (the increase in quantity/density, dominance of clay objects in clusters inside buildings and alongside other artefacts) date to this point in time. The late Neolithic sees a range of cultural developments including the emergence of nomadic pastoralism, an intensification of secondary product use, an increase in pottery use for storage, the rise of decorated pottery and the shift in settlements from the Balikh Valley into the wider steppes (Bar-Yosef \& Khazanov 1992; Campbell 2017; Levy 1983; Nieuwenhuyse pers. com.; Nieuwenhuyse and Akkermans forthcoming; Nieuwenhuyse et al. 2010). In this context, it is fitting that the use of clay objects would intensify and develop, according to the changing needs of the communities that used them.

Halaf levels at $6^{\text {th }}$ millennium BC Tell Arpachiyah display clay objects along with sealings and stamp-seals, the majority of which come from level 6 of the summit/TT area of the site (Campbell 2000: 2-25; Schmandt-Besserat 1992a; 1992b). 
Dating to c. 5,300 BC, a large building here shares many similarities to Sabi Abyad's operation II lower sequence, burnt T-shaped building. Tell Arpachiyah's level 6 TT building was burnt and contained a wide variety of finds, numbering more than 150 pieces (Campbell 2000: 2). The finds were mostly distributed across just two rooms. In addition to finely crafted polychrome pottery plates, stone vessels and beads of exotic, imported raw materials and at least 11 stamp-seals and 27 clay sealings were recovered (Campbell 2000: 8-23, 26-38). The sealings are found in various forms, some of which bear similarities to CO\#105 from Sabi Abyad (Denham 2013). Due to contextual similarities it is tempting to interpret the clay objects from Tell Arpachiyah as part of a ritual building burning phenomenon of the late Neolithic of upper Mesopotamia (Verhoeven 2000).

\section{Conclusion}

The intentional craft, presence in large numbers, and contextual deposition of clay objects at Tell Sabi Abyad, points to them having been utilitarian tools, as opposed to children's plaything, 'doodles' in clay or naturally formed shaped 'lumps'. Rather than a singular, consistent function across the site's 1,800 year occupation, clay objects clearly had multiple functions, most now archaeologically ambiguous. One of their uses, clearly attested at level 6 of operation I and at operation II c. 6,000 BC is as counting tools aiding administrative activities. The findings of this study therefore, supporting the overall interpretation of Schmandt-Besserat (1992a; 1996), yet differ in detail in a number of ways. Watkins $(2006 ; 2010 ; 2012)$ and others have argued that Neolithic villagers were capable of utilizing sets of objects, recursively, in order to transmit language, data and abstract concepts (Donald 1991; Renfrew 1998; 2007; 2012; Schmandt-Besserat 1992a, 1996). 
Whilst I argue that clay objects were likely used as counters (c. 6,000 BC), there is no evidence at Sabi Abyad, to suggest clay objects were used to store non-numerical information, certainly not in a standardized, methodological system of representation and long-term information storage. Three-dimensional shapes could easily have served as a way of distinguishing resultant sets of clay objects, having an impromptu, specific meaning on a short-term basis. Yet there is no evidence of a site-wide symbolic system linked to the shape of clay objects at Tell Sabi Abyad, not even in the later phases of occupation.

Careful analysis of Sabi Abyad's clay objects proves a number of additional common assumptions related to the use of so-called 'tokens' to be incorrect. Firstly, Schmandt-Besserat's theory claims clay objects appear simultaneously with agricultural villages at the start of the Neolithic; and from this point onwards, their sole purpose was as administrative tools (1992a: 99, 161-162, 166-68, 170, 172, 198; 1996: 7, 29, 100, 102). Though present from the PPNB at Sabi Abyad, evidence for the administrative use of clay objects comes late in the sequence. Pre 6,000 BC, clay objects must have operated in a different sphere.

An increase in 'token' numbers through time within the Neolithic, within and across sites is proposed (Schmandt-Besserat: 1992a, 1996). This is linked to an apparent corresponding diversification of Neolithic village economies. There is no evidence of this trend when considering data from a large number of Neolithic sites across the Near East region (Bennison-Chapman 2019), and certainly not within the more limited timeframe of Sabi Abyad's occupation. Painstakingly detailed chronological analysis, analysing the quantity, manufacture, appearance and contextual distribution of a huge data-set, level-by-level and across various occupation zones of a 1,800 year period at Sabi Abyad shows no evolution in form, nor gradual take-up of a 'token' technology. 
Instead, c. 6,000 BC, the villagers of Tell Sabi Abyad I's operations I and II engaged in an activity, necessitating the large-scale use of small, geometric clay objects. The corresponding increase in secured storage facilities and shared contextual deposition of clay objects and artefacts related to storage and administration, places clay objects at the location of likely counting and other administrative activities. The evidence from Sabi Abyad is mirrored by other Halaf sites (namely Tells Arpachiyah and Halaf: BennisonChapman 2014: chapter 9.4(a), fig. 9.26-9.30; Campbell 2000: 2-25).

Despite its 1,800 year-long occupation, evidence suggests the use and deposition of clay objects in administration at Sabi Abyad was a short-lived phenomenon, restricted to two small occupational zones spanning just two to three generations from $\mathrm{c}$. 6,000 BC. At this point in time, clay objects were used, and possibly retained for a limited period, before being disposed of in groups, alongside other administrative tools. Thus this study successfully pinpoints the point at which clay objects begin to be used as tools in administration in the Near East. Differing from the hypothesis of SchmandtBesserat (1992a, 1996), this study shows how detailed, chronologically sound, stratigraphic-based research can be used to test and clarify theories proposed by others. Though broad-scale studies of large numbers of sites covering a wide time-period may at first seem convincing, theories such as the appearance and development of 'tokens' can only be tested and refuted/substantiated by detailed and systematic analysis of the quantity, form and context of individual artefacts on a stratigraphic level-by-level basis. The lack of patterning in any aspect of clay object form, use, distribution or disposal throughout most of the site's 1,800 year-long occupation, nor within or across other sites of the Neolithic Near East (Bennison-Chapman 2019), points of the lack of a singular, consistent function of these artefacts. As the majority of Sabi Abyad's clay 
objects were found as singular deposits in ambiguous open-air contexts, their function and use in the sites early phases of occupation remains archaeologically ambiguous. The function was likely fluid and short lived during the bulk of occupation at Tell Sabi Abyad. Social, economic and ritual changes at the end of the $7^{\text {th }}$ millennium BC, across upper Mesopotamia prompted the need for clay objects as counting tokens, in a basic, one-to-one method of quantification.

[WORD COUNT: 12,074]

\section{Acknowledgements}

I would like to thank the Gerald Averay Wainwright Fund for Near Eastern Archaeology for supporting the publication of this research with a research grant. Primary and secondary research was also supported by the Council for British Research in the Levant, and a travel grant awarded by the School of Archaeology, Classic and Egyptology, University of Liverpool. Many thanks to the help received by various members of the Tell Sabi Abyad team, especially project director Prof. P.M.M.G. Akkermans, Dr O.P. Nieuwenhuyse and Merel Brüning.

\section{Bibliographical note}

Lucy Bennison-Chapman studied Near Eastern archaeology at the University of Liverpool, graduating in 2015. Her main research interest centres on the development of complex societies; the social developments that commenced with the appearance of sedentism and agriculture in Neolithic; culminating in the appearance of the complex, literate city-states in the $3^{\text {rd }}$ millennium BC. She has undertaken fieldwork in Syria, Kuwait and Turkey, where she remains an active team member of the Boncuklu Höyük Project (directed by Prof. Baird, University of Liverpool). Lucy spent two-years undertaking a teaching and research position at Bülent Ecevit University, Zonguldak (Turkey). In September 2019, she will take up the position of NINO Postdoctoral Fellow at the Netherlands Institute for the Near East, Leiden, Netherlands.

\section{References}

Akkermans, P. M. M. G. (ed.). 1989a. Excavations at Tell Sabi Abyad: Prehistoric investigations in the Balikh Valley, northern Syria. BAR International Series 468: Oxford. 
Akkermans, P. M. M. G. 1989b. The Neolithic of the Balikh Valley, Northern Syria: A First Assessment. Paléorient 15/1: 122-34.

Akkermans, P. M. M. G. 1991. New Radiocarbon Dates for the Later Neolithic of Northern Syria. Paléorient 17/1: 121-25.

Akkermans, P. M. M. G. 1993. Villages in the Steppe: Later Neolithic Settlement and Subsistence in the Balikh Valley, Northern Syria. International Monographs in Prehistory. Ann Arbor: Michigan.

Akkermans, P. M. M. G. (ed.). 1996a. Tell Sabi Abyad, The Late Neolithic Settlement: Report on the Excavations of the University of Amsterdam 1988 and the National Museum of Antiquities Leiden 1991-1993 in Syria-Volume I. Nederlands Historisch-Archaeologisch Instituut te Istanbul: Istanbul. Akkermans, P. M. M. G. (ed.). 1996b. Tell Sabi Abyad, the Late Neolithic Settlement: Report on the Excavations of the University of Amsterdam 1988 and the National Museum of Antiquities Leiden 1991-1993 in Syria-Volume II. Nederlands Historisch-Archaeologisch Instituut te Istanbul: Istanbul.

Akkermans, P. M. M. G. \& Duistermaat, K. 1996. Of storage and Nomads. The sealings from Late Neolithic, Sabi Abyad, Syria [with comments and reply]. Paléorient 22/2: 17-44.

Akkermans, P. M. M. G. \& Duistermaat, K. 2004. More Seals and Sealings from Neolithic Tell Sabi Abyad, Syria. Levant 36: 1-11.

Akkermans, P. M. M. G. \& Verhoeven, M. 1995. An Image of Complexity: The Burnt Village at Late Neolithic Sabi Abyad, Syria. American Journal of Archaeology 99/1: 5-32.

Akkermans, P. M. M. G., Brüning, M., Hammers, N., Huigens, H., Kruijer, L., Meens, A., Nieuwenhuyse, O., Raat, A., Rogmans, E. F., Slappendel, C., Taipale, S., Tews, S. \& Visser, E. 2012. Burning Down the House: the burnt building V6 at Late Neolithic Tell Sabi Abyad, Syria. Analecta Praehistorica Leidensia 43/44: 307-24.

Akkermans, P. M. M. G., Brüning, M., Huigens, H. \& Nieuwenhuyse, O. eds. 2014. Excavations at Late Neolithic Tell Sabi Abyad, Syria: The 1994-1999 field seasons. Brepolis: Turnholt.

Akkermans, P.M.M.G., Cappers, R., Cavallo, C., Nieuwenhuyse, O., Nilhamn, B. \& Otte, I.N. 2006. Investigating the Early Pottery Neolithic of Northern Syria: 
New evidence from Tell Sabi Abyad. American Journal of Archaeology 110/1 Jan: 123-56.

Akkermans, P., van der Plicht, J., Nieuwenhuyse, O., Russell, A., Kaneda, A. \& Buitenhuis, H. 2010. Weathering Climate Change in the Near East: Dating and Neolithic adaptations 8200 years ago. Antiquity: Project Gallery 325/325. Amiet, P. 1966. Elam Auvers-Sur-Oise: Archée.

Baird, D. 2016. Boncuklu: the spread of farming and the antecedents of Çatalhöyük. Heritage Turkey 6: 15-18.

Bar-Yosef, O. \& Khazanov, A. 1992. Pastoralism in the Levant: Archaeological Perspectives. Prehistory Press: Madison.

Bennison-Chapman 2019. Reconsidering 'Tokens': The Neolithic origins of accounting or multifunctional, utilitarian tools? Cambridge Journal of Archaeology 29/2: 233-59.

Bennison-Chapman, L.E. 2014. The Role and Function of 'Tokens' and Sealing Practices in the Neolithic of the Near East: The question of early recording systems, symbolic storage, precursors to writing, gaming, or monitoring devices in the world's first villages. PhD Dissertation. University of Liverpool, UKBroman Morales, V. 1983. Jarmo Figurines and other Clay Objects. In, Braidwood, L. S., Braidwood, R. J., Howe, B., Reed, C. A. \& P. J. Watson (eds), Prehistoric Archaeology along the Zagros Flanks: 369-423. Oriental Institute of the University of Chicago: Chicago.

Broman Morales, V., 1990. Figurines and Other Clay Objects from Sarab and Çayönü. The Oriental Institute of the University of Chicago: Chicago.

Broman, V. 1958. Jarmo Figurines. Masters Dissertation. University of Cambridge. Brown, S., 1996. Review of Schmandt-Besserat, D. Before Writing, Volumes I \& II, 1992. Canadian Society for Mesopotamian Studies Bulletin 31: 35-43.

Campbell, S. 2017. Absolute Dating and the Early Pottery of South-West Asia. In, Akira, T., Nieuwenhuyse, O. \& Campbell, S. (eds), The Emergence of Pottery in West Asia: 133-54. Oxbow Books: Oxford/Philadelphia.

Campbell, S. 2000. The Burnt House at Arpachiyah: A reexamination, Bulletin of the American Schools of Oriental Research 318: 1-40.

Childe, V. G. 1936. Man Makes Himself. Watts: London. 
Çilingiroğlu, A., Derin, Z., Abay, E., Sağlamtimur, H. \& Kayan, I. 2004. Ulucak Höyük: Excavations conducted between 1995 and 2002. Peeters: Louvain-ParisDudley, MA.

Cole, G., R. Matthews \& A. Richardson, 2013. Material Networks of the Neolithic at Sheikh-e Abad: Objects of bone, stone and clay. In, Matthews, R., Mohammadifar, Y. \& Matthews, W. (eds), The Earliest Neolithic of Iran: 2008 excavations at Sheikh-e Abad and Jani (CZAP Reports Vol. 1): 135-45. Oxford: Oxbow.

Costello, S. K., 2011. Image, Memory and Ritual: Re-viewing the Antecedents of Writing. Cambridge Archaeological Journal 21/2: 247-62.

Costello, S.K., 2000. Memory Tools in Early Mesopotamia. Antiquity 74, 475-6.

Costello, S.K. 2002. Tools of Memory: Investigation of the context of information storage in the Halaf period. PhD Dissertation. Binghamton University, USA Damerow, P., 1993. Bookkeepers Invented Scripture: Review of SchmandtBesserat's Before Writing 1992. Rechtshistorisches Journal 12/6):9-35.

Denham, S., 2013. The Meanings of Late Neolithic Stamp Seals in North Mesopotamia. PhD Dissertation. University of Manchester, UK.

Donald, M. 1991. Origins of the Modern Mind: Three stages in the evolution of culture and cognition. Harvard University Press: Cambridge Massachusetts \& London, England.

Duistermaat, K. 1996. The Seals and Sealings. In, Akkermans, P.M.M.G. (ed.), Tell Sabi Abyad, the Late Neolithic Settlement: Report on the Excavations of the University of Amsterdam 1988 and the National Museum of Antiquities Leiden 1991-1993 in Syria: 339-402. Nederlands Historisch-Archaeologisch Instituut te Istanbul: Istanbul. Duistermaat, K. \& Schneider, G. 1998. Chemical Analyses of Sealing Clays and the Use of Administrative Artefacts at Late Neolithic Tell Sabi Abyad Syria. Paléorient 24/1: 89-106.

Duru, R. \& Umurtak, G. 2005. Höyücek. 1989-1992 Yılları Arasında Yapılan Kazıların Sonuçları 2005 Höyücek. Results of the Excavations 1988-1992. Türk Tarih Kurumu Yayınları: Ankara.

Eslick, C. \& Voight, M., 2017. Some Clay Finds from PPNB Gritille: Stamps, sealings and tokens. In Kozal, E., Akar, M., Heffron, Y., Çilingiroğlu, Ç., Şerifoğlu, E., Çakrlar, C., Ünlüsoy, S. \& Jean, E (eds), Questions, Approaches, and Dialogues 
in Eastern Mediterranean Archaeology: Studies in honour of Marie-Henriette and Charles Gates: 77-96. Ugarit-Verlag: Münster.

Englund, R.K., 1993. The Origins of Script. Review of Before Writing by Denise Schmandt-Besserat. Science 260(5114): 1670-71.

Englund, R.K., 1998. Review of D. Schmandt-Besserat, How Writing Came About. Written Language and Literacy 1: 257-61.

Finlayson, B., Kuijt, I., Mithen, S. \& Smith, S. 2011. New Evidence from Southern Jordan: Rethinking the Role of Architecture in Changing Societies at the Beginning of the Neolithic Process. Paléorient 37/1: 75-135.

Finlayson, B., Mithen, S. J., Najjar, M., Smith, S., Maričević, D., Pankhurst, N. \& Yeomans, L., 2011. Architecture, Sedentism, and Social Complexity at PrePottery Neolithic A WF16, Southern Jordan. Proceedings of the National Academy of Sciences 108/20: 8183-88.

Forouzan, F., Glover, J. B., Williams, F. \& Deocampo, D. 2012. Portable XRF Analysis of Zoomorphic Figurines, 'Tokens', and Sling Bullets from Chogha Gavaneh, Iran. Journal of Archaeological Science 39/12: 3534-41.

Friberg, J., 1994. Preliterate Counting and Accounting in the Middle East: A constructively critical review of Schmandt-Besserat's Before Writing. Orientalistische Literaturzeitung 89/5-6: 477-502.

Herskovits, M. J. 1932. Population Statistics in the Kingdom of Dahomey. Human Biology 4/2: 252-61.

Kenyon, K. M., \& Holland, T. A., 1982 Excavations at Jericho Volume 4: The Pottery Type Series and Other Finds. British School of Archaeology in Jerusalem: London.

Kenyon, K. M. \& Holland, T. A., 1983. Excavations at Jericho Volume 5: The Pottery Phases of the Tell and Other Finds. British School of Archaeology in Jerusalem c/o The British Academy: London.

Kuijt, I. 2011. Home is where we keep our food: The origins of agriculture and LatePre-pottery Neolithic food storage. Paléorient 37/1: 137-52.

Leo Oppenheim, A. 1959. On an Operational Device in Mesopotamian Bureaucracy. Journal of Near Eastern Studies 18/2: 121-128.

Levy, T. 1983. The Emergence of Specialized Pastoralism in the Southern Levant. World Archaeology 15/1: 15-36. 
Mahasneh, H.M. \& Gebel, H.G. 1998. Geometric Objects from LPPNB Es-Sifiya, Wadi Mujib, Jordan. Paléorient 24/2: 105-10.

Matthews, R., Matthews, W. \& Mohammadifar, Y. (eds.), 2013. The Earliest Neolithic of Iran: 2008 Excavations at Sheikh-E Abad and Jani (CZAP Reports Vol. 1). Oxbow Books: Oxford.

Merpert, N. Ya. \& Munchaev, R. M., 1987. The Earliest Levels at Yarim Tepe I and Yarim Tepe II in Northern Iraq. Iraq 49: 1-36.

Michalowski, P. 1993. Review: Tokenism: Before Writing, Volume 1: From Counting to Cuneiform by Denise Schmandt-Besserat; Before Writing, Volume 2: A Catalog of Near Eastern Tokens by Denise Schmandt-Besserat, American Anthropologist, 95/4: 996-999.

de Morgan, J., Jéquier, G., de Mecquenem, R., Haussoulier, B. \& Graat van Roggen, D.-L. 1905. Mémoires de la Délégation en Perse, 7, Recherches archéologiques, zème série. Editions Ernst Le Roux, Paris.

Nashli, H.F. \& Moghimi, N. 2013. Counting Objects: New evidence from Tepe Zagheh, Qazvin plain, Iran. Antiquity Project Gallery 87/336.

Netz, R. 2002. Counter Culture: Towards a History of Greek Numeracy. History of Science, 40/3: 321-52.

Nieuwenhuyse, O. P. 2018. Relentlessly Plain: Seventh Millennium Ceramics at Tell Sabi Abyad. Oxbow: Oxford.

Nieuwenhuyse, O. P. \& Akkermans, P. M. M. G. Forthcoming. Transforming the Upper Mesopotamian landscape in the Late Neolithic. In, Marciniak, A. (ed.), Concluding the Neolithic: The Near East in the Second Half of the Seventh Millennium BC. Atlanta: Lockwood Press.

Nieuwenhuyse, O. P., Akkermans, P. M. M. G. \& van der Plicht, J. 2010. Not so coarse, nor always plain-the earliest pottery of Syria. Antiquity 84/323: 71-85.

Nissen, H.J., Damerow, P. \& Englund, R.K. 1993. Archaic Bookkeeping: Early Writing and Techniques of Economic Administration in the Ancient Near East. Chicago: University of Chicago Press.

Oates, J., 1978. Religion and Ritual in Sixth-Millennium B.C. Mesopotamia. World Archaeology 10/2: 117-24.

Özbal, R., Gerritsen, F., Diebold, B., Healey, E., Aydin, N., Loyette, M., Nardulli, F., Reese, D., Ekstrom, H. \& Sholts \& S. 2004. Tell Kurdu Excavations 2001. Anatolica 30: 37-107. 
Pitman, H. 1996 Preliminary Report on the Glyptic Art: Hacinebi, 1993. In, Stein, G. et al. Uruk Colonies and Mesopotamian Communities: An Interim Report on the 1992-3 Excavations at Hacinebi, Turkey. American Journal of Archaeology 100/2: 230-33.Redman, C. 1977. Man, Domestication, and Culture in Southwestern Asia. In, Reed, C. A. (ed.), Origins of Agriculture: 879-41. Moulton: The Hague/Paris.

Renfrew, C. 1998. Mind and Matter: Cognitive Archaeology and External Symbolic Storage. In, Renfrew, C. \& Scarre, C. (eds), Cognition and Material Culture: The archaeology of symbolic storage: 1-6. McDonald Institute for Archaeological Research: Cambridge.

Renfrew, C. 2007. Prehistory-The making of the human mind. Phoenix: London.

Renfrew, C. 2012. Towards a Cognitive Archaeology: Material engagement and the early development of society. In, Hodder, I. (ed), Archaeological Theory Today: 124-45. Polity Press: Cambridge UK \& Malden, MA, USA.

Richardson, A. 2014. Early Clay Technologies: Studies in Early Neolithic clay usage from the Central Zagros. In, Bieliński, P., Gawlikowski, M., Koliński, R., Ławecka, D., Sołtysiak, A., \& Wygnańska, Z. (eds), Proceedings of the 8th International Congress on the Archaeology of the Ancient Near East, 30 April-4 May 2012, University of Warsaw Volume 1: Plenary Sessions, Township and Villages, High and Low - The Minor Arts for the Elite and for the Populace: 4153. Wiesbaden: Harrassowitz.

Robinson, A. 2007. The Story of Writing: Alphabets, Hieroglyphs and Pictograms. Thames \& Hudson: London.

Rollefson, G., 1986. Neolithic 'Ain Ghazal (Jordan): Ritual and ceremony, II. Paléorient 12/1: 45-52.

Sampson, G. 1985. Writing Systems: A linguistic introduction. Stanford: Stanford University Press.

Schmandt-Besserat, D. 1978a. The Earliest Precursor of Writing. Scientific American 238/6: 50-59.

Schmandt-Besserat, D. 1978b. Reckoning Before Writing. Archaeology 32/3: 22-31. Schmandt-Besserat, D. 1979. An Archaic Recording System in the Uruk-Jemdet Nasr Period. American Journal of Archaeology 83/1: 19-48.

Schmandt-Besserat, D. 1981. From Tokens to Tablets: A Re-evaluation of the so-called Numerical Tablets. Visible Language 15/4: 321-344. 
Schmandt-Besserat, D. 1982. The Emergence of Recording. American Anthropologist 84/4: 871-878.

Schmandt-Besserat, D. 1992a. Before Writing, Volume I: From Counting to Cuneiform. University of Texas Press: Austin.

Schmandt-Besserat, D. 1992b. Before Writing, Volume II: A Catalogue of Near Eastern Tokens. University of Texas Press: Austin.

Schmandt-Besserat, D. 1996. How Writing Came About. University of Texas Press: Austin.

Simmons, A. H. \& Najjar, M., 2006. Ghwair I: A Small, complex Neolithic community in Southern Jordan. Journal of Field Archaeology 31/1: 77-95.

Simpson, S. J. 2007. Homo Ludens: The Earliest Board Games in the Near East. In, Finkel, I.L. (ed), Ancient Board Games in Perspective: Papers from the 1990 British Museum colloquium, with additional contributions: 5-10. The British Museum Press: London.

Spoor, R. \& Collet, P. 1996. Other Small Finds. In, Akkermans, P.M.M.G. (ed.), Tell Sabi Abyad, the Late Neolithic Settlement: Report on the Excavations of the University of Amsterdam 1988 and the National Museum of Antiquities Leiden 1991-1993 in Syria: 439-74. Nederlands Historisch-Archaeologisch Instituut te Istanbul: Istanbul.

Tekin, H. 2007. Hakemi Use: Güneydoğu Anadolu'da Son Neolitik Döneme Ait Yeni Bir Merkez. In, Özdoğan, M. \& Basgelen, N. (eds), Anadolu'da Uygarligin Dogusu ve Avrupa'ya Yayilimi: Türkiye'de Neolitik Dönem: Yeni Kazılar, Yeni Bulgular. Vol 2: Levhalar: 41-52. Arkeoloji ve Sanat Yayınları: Istanbul.

Salat Camii Yanı Project, University of Tsukuba. 2010. Small Finds in Salat Cami Yani: Excavations of a Pottery Neolithic Site in the Upper Tigris Valley. Available at:

http://rcwasia.hass.tsukuba.ac.jp/scy/research/smallfinds.html (accessed 6 November 2015).

Various. 1988-2010. Tell Sabi Abyad Research Project. Unpublished field notes and excavation archives. Leiden: Department of Archaeology, The University of Leiden and The National Museum of Antiquities, Leiden.

Verhoeven, M., 2007. Losing One's Head in the Neolithic: On the Interpretation of Headless Figurines. Levant 39/1: 175-83. 
Verhoeven, M. 1999. An Archaeological Ethnography of a Neolithic Community:

Space, Place and social relationships in the Burnt Village at Tell Sabi Abyad, Syria. Nederlands Historisch-Archaeologisch Instituut te Istanbul: Istanbul.

Verhoeven, M. 2000. Death, Fire and Abandonment: Ritual practice at Late Neolithic Tell Sabi Abyad, Syria. Archaeological Dialogues 7/1: 46-65.

Verhoeven, M. 2011. The Birth of a Concept and the Origins of the Neolithic: A history of prehistoric farmers in the Near East. Paléorient 37/1: 75-87.

Verhoeven, M. \& Akkermans, P. M. M. G. eds. 2000. Tell Sabi Abyad II: The PrePottery Neolithic B Settlement. Nederlands Historisch-Archaeologisch Instituut te Istanbul: Istanbul.

Voigt, M.M. 1983. Hajji Firuz Tepe, Iran: The Neolithic Settlement. University of Pennsylvania Museum of Archaeology \& Anthropology: Philadelphia.

Watkins, T. 2006. Architecture and the Symbolic Construction of New Worlds. In, Banning, E.B \& Chazan, M. (eds), Domesticating Space: 15-24. Ex Oriente: Berlin.

Watkins, T. 2010. New light on Neolithic Revolution in South-West Asia. Antiquity 84/325: 621-34.

Watkins, T. 2012. Household, Community and Social Landscape: Maintaining social memory in the Early Neolithic of Southwest Asia. In, Furholt, M., Hinz, M. \& Mischka, D. (eds), As Time Goes By? Monuments, Landscapes and the Temporal Perspective. Proceedings of the International Workshop SocioEnvironmental Dynamics over the Last 12,000 Years: The Creation of Landscapes II, 14th-18th March 2011 in Kiel. Volume 2: 23-44. Verlag Dr. Rudolf Habelt GmbH: Bonn.

Woods, C. (ed.). 2010 Visible Language: Inventions of writing in the ancient Middle East and beyond. The Oriental Institute of the University of Chicago, Chicago. 


\section{Illustrations}

\section{Figures}
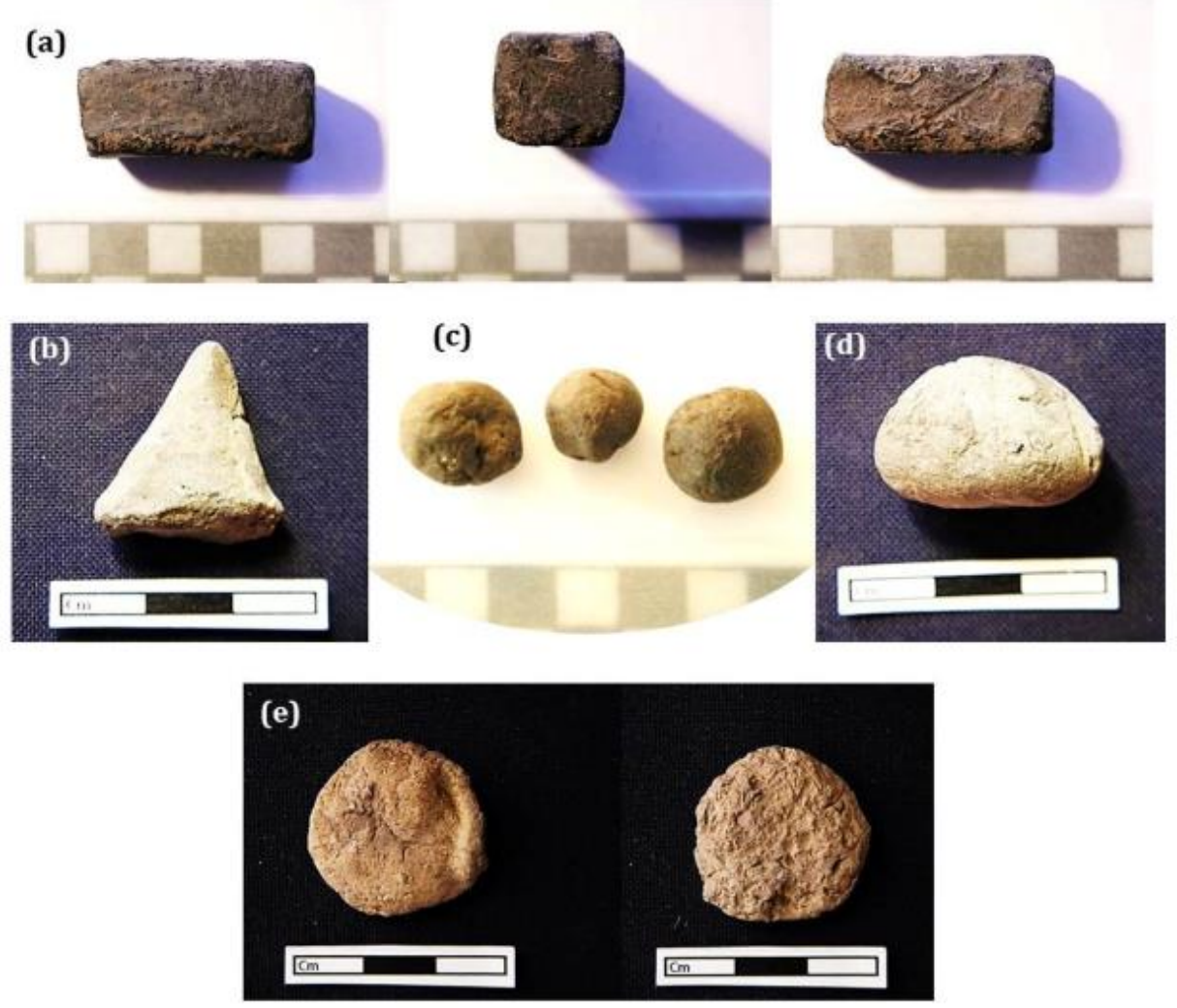

(f)
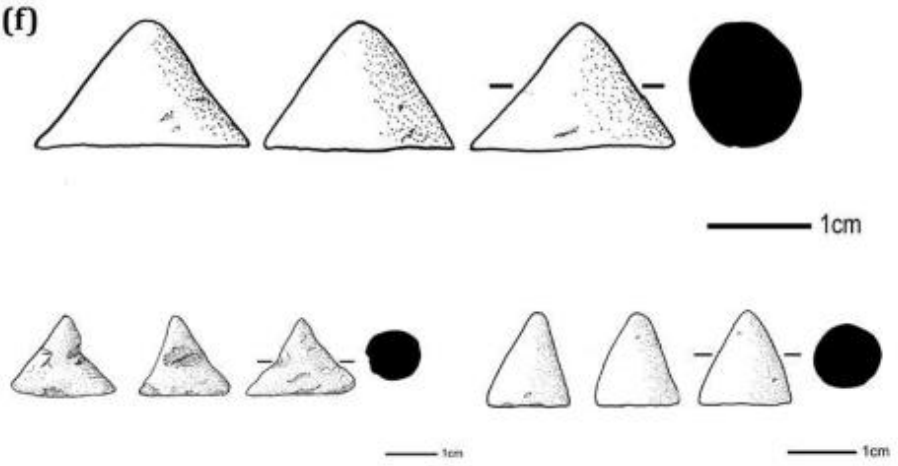

Figure 1. Illustrative examples of the range of small geometric clay objects which appeared at sites across the Near East from the start of the Neolithic period c. $10^{\text {th }}$ millennium BC All examples shown here fall into Schmandt-Besserat's plain token category. (a) A cuboid, from $8^{\text {th }}-7^{\text {th }}$ millennium BC Çatalhöyük, Central Anatolia. Clay Object Number (henceforth CO\#) 1283. (b) A triangular-shaped clay object from $9^{\text {th }}-8^{\text {th }}$ millennium BC Boncuklu Höyük, Central Anatolia; CO\# 1483. (c) A selection of small clay spheres from Çatalhöyük; CO\#s 344, 345 \& 346. (d) A semi-sphere from Boncuklu Höyük; CO\# 1515. (e) The front and reverse of a discshaped clay object from Boncuklu Höyük; CO\# 1440. (f) A range of cones from Çatalhöyük. CO\#s 1080, 1120 and 1151. (Photographs: author's own. Drawings: Mesa Schumacher, courtesy of the Çatalhöyük Project). 


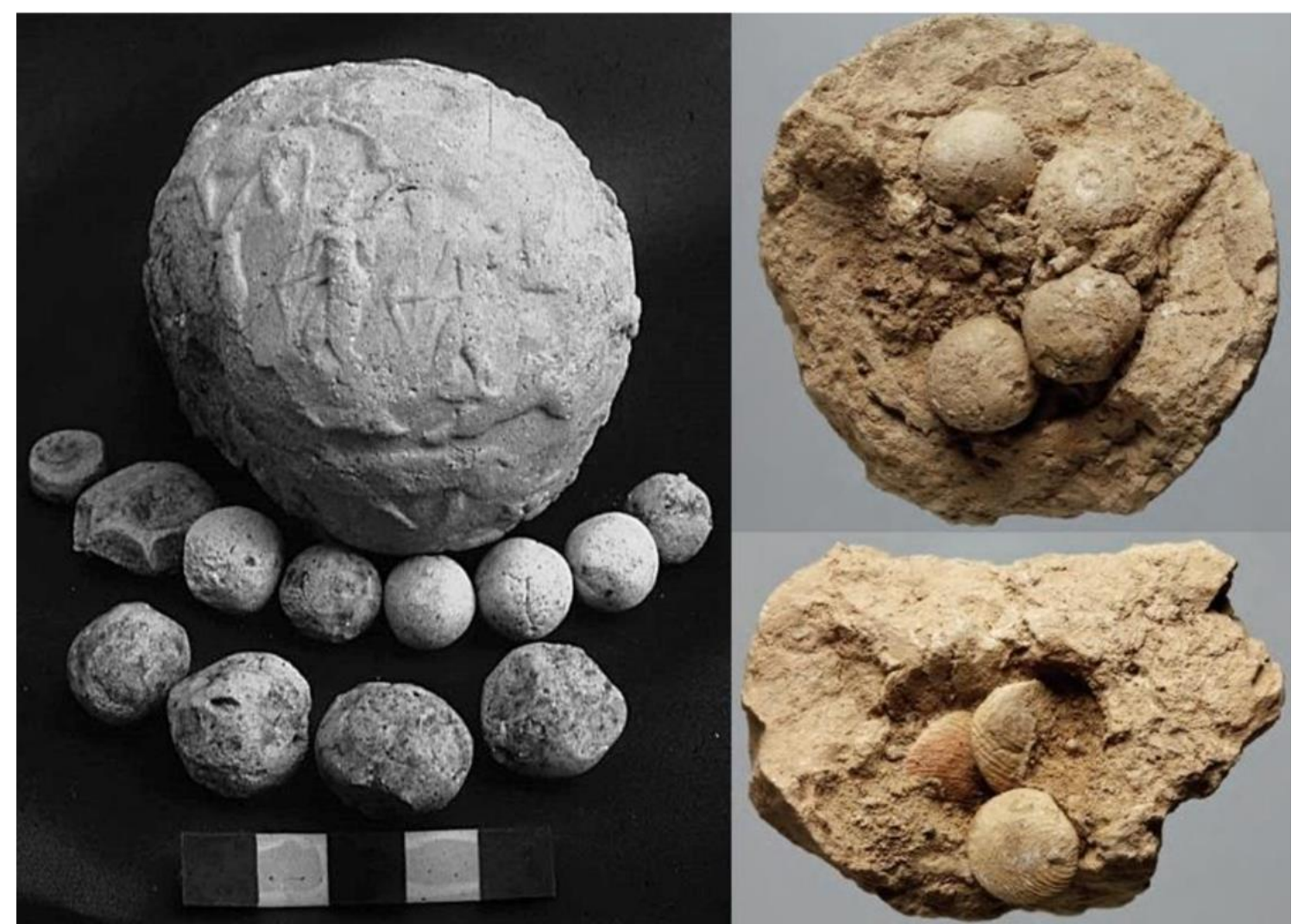

Figure 2. Examples of a clay bullae (envelopes) recovered with tokens inside. Left: bulla with cylinder seal impressions. From Hacinebi, southeast Anatolia/upper Mesopotamia, late $4^{\text {th }}$ millennium BC. Diameter $7.80 \mathrm{~cm}$. Inside were 12 'tokens' $(1.00-2.50 \mathrm{~cm})$ of four different shapes: six small spheres, four large spheres, one disc and one lentoid. The disc displays a single linear incision across one surface (Pitman 1996: fig 18a p. 231). Right: two opened bullae displaying the spherical (top) and disc-shaped (bottom) geometric clay objects which were recovered sealed inside. From late $4^{\text {th }}$ millennium BC Choga Mish, Iran. (After Woods 2010: $\operatorname{nos} 32 \& 33$ p. 66). 


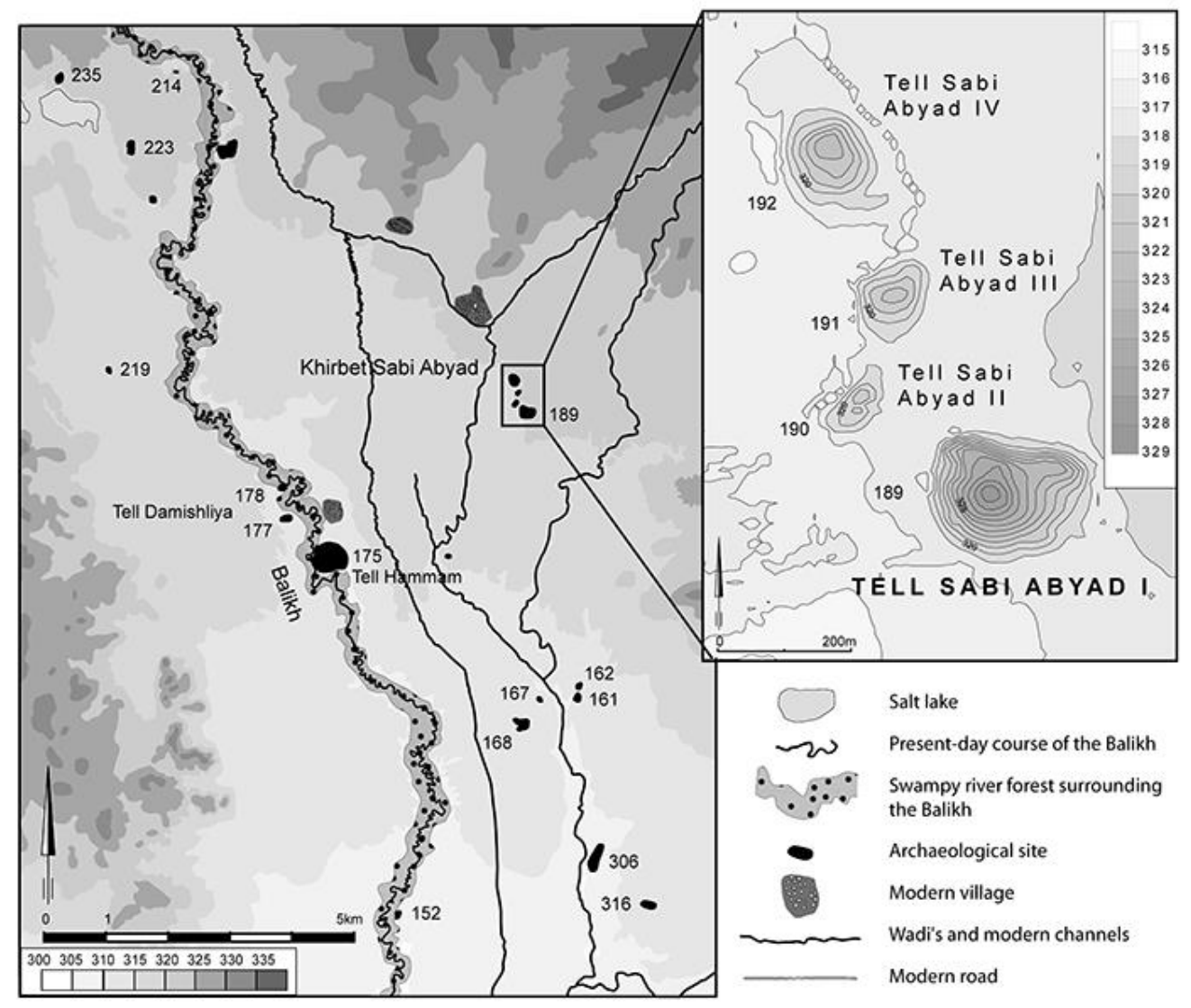

Figure 3. A map modern day Syria within the wider Middle East region, showing the location of Tell Sabi Abyad. (Image courtesy of the Tell Sabi Abyad Research Project). 


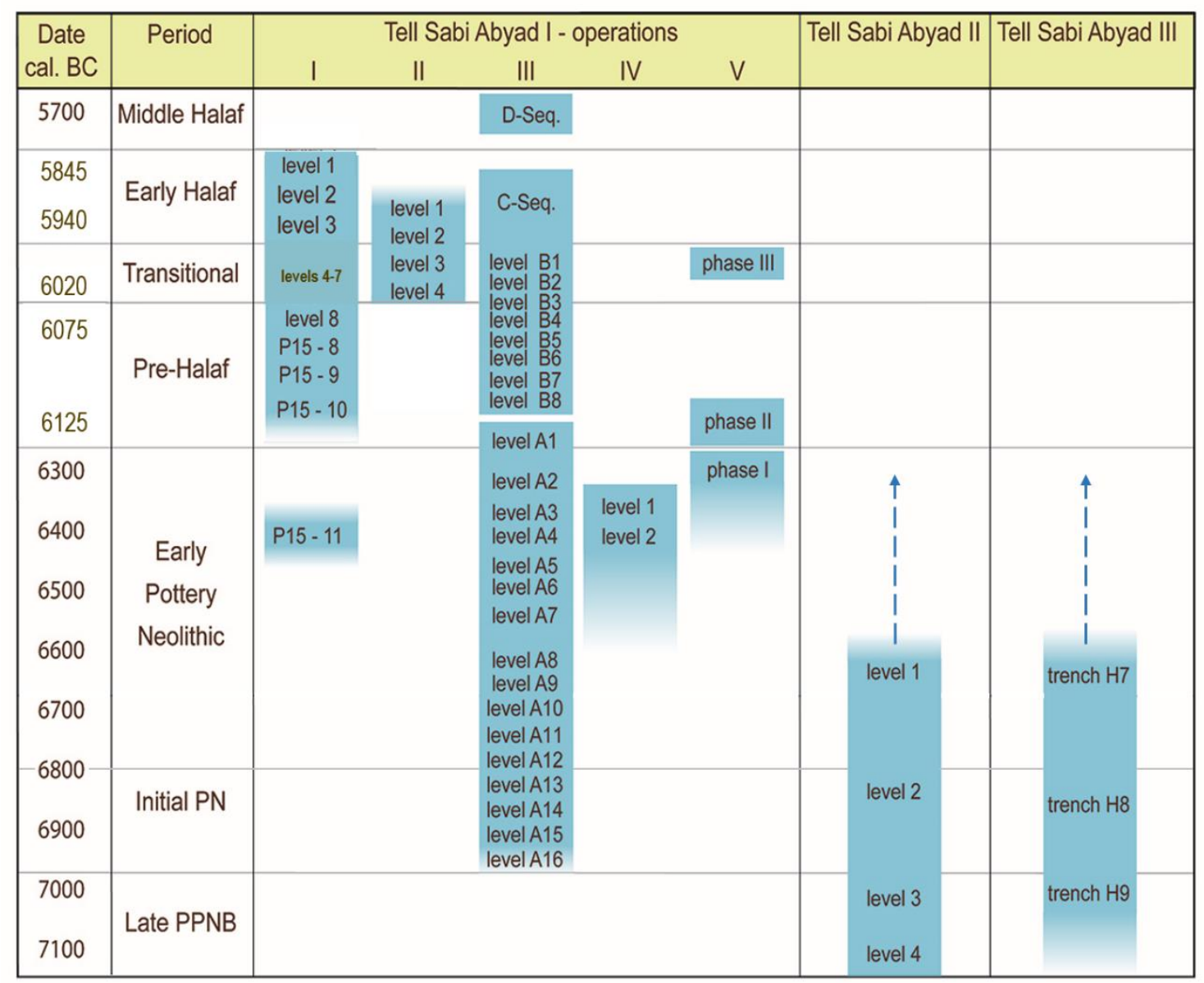

Figure 4. Chronological chart of Neolithic Tell Sabi Abyad, detailing the main sequence of occupational levels and broad cultural phases with date boundaries. Note the earliest occupation phase, commencing c. 7,550 BC, on Sabi Abyad II is not shown. (Adapted from Nieuwenhuyse et al. 2010: fig. 5 p. 78 and Akkermans et al. 2014: table 1.3 p. 28). 


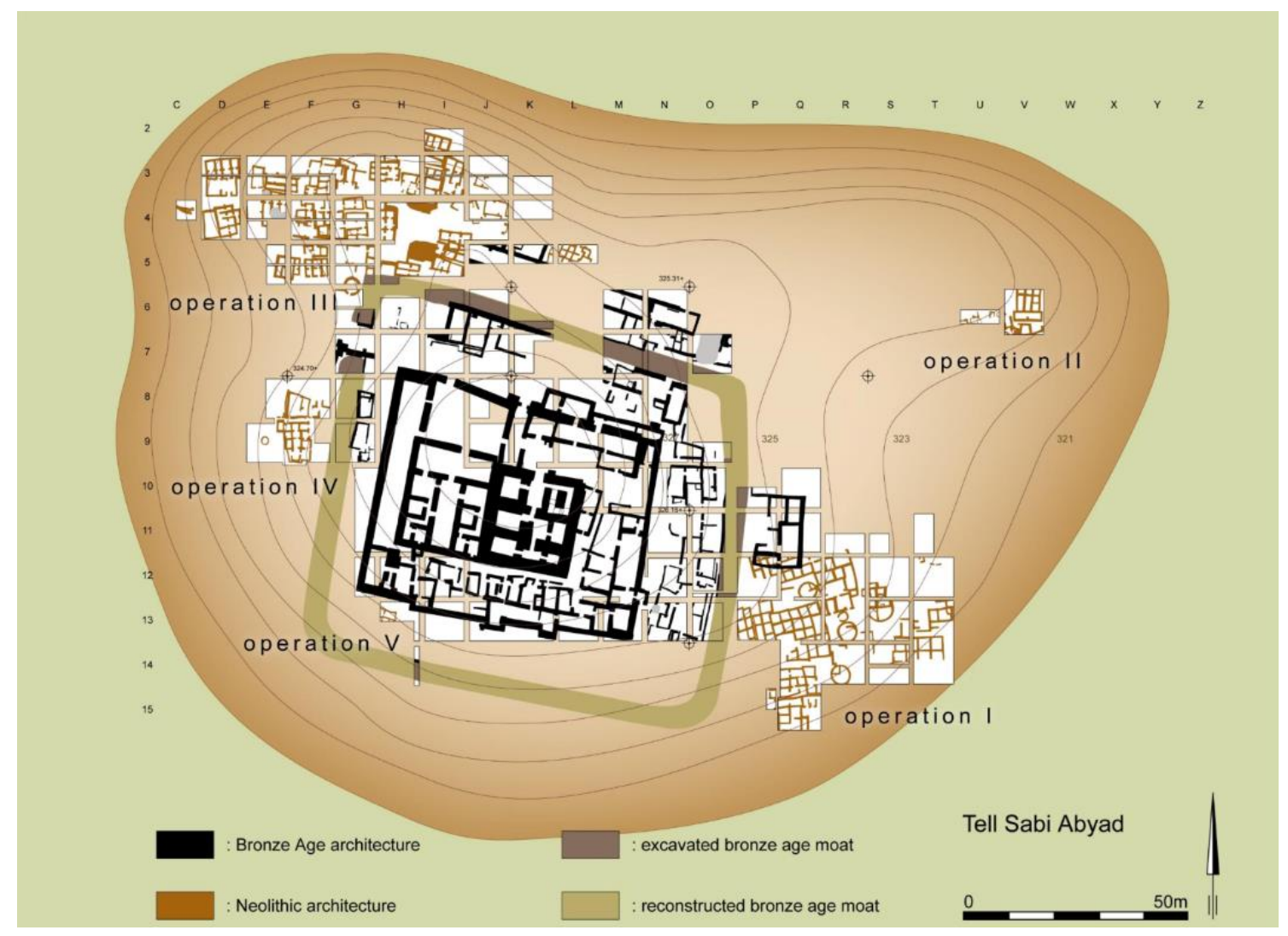

Figure 5. A plan of Tell Sabi Abyad I with the five excavation areas ('operations') within it marked (Tell Sabi Abyad Research Project). 


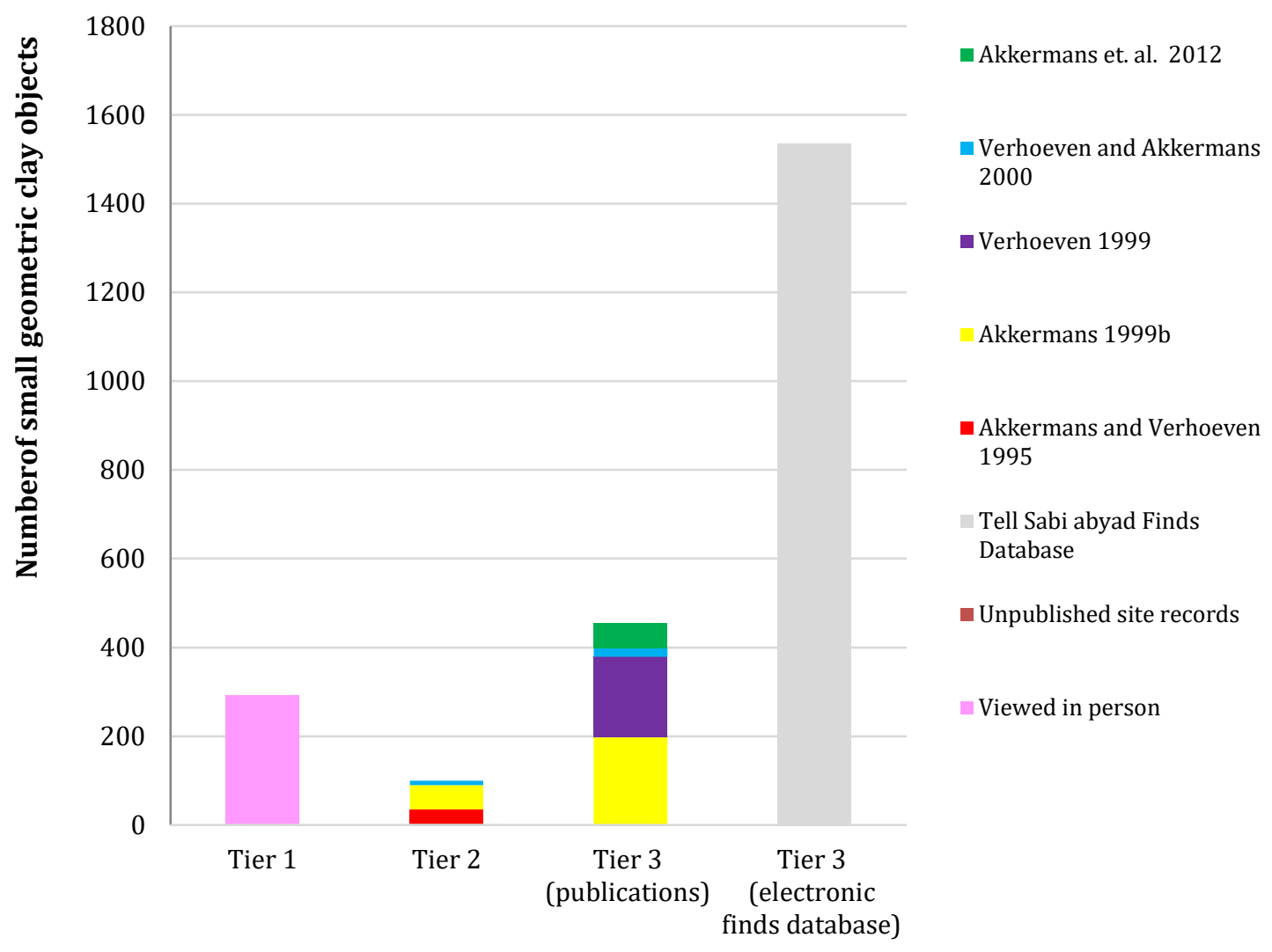

Level of object recording

Figure 6. Total number of clay objects studied according to tier of recording and data source.

Tier 1: $n=293$ (all viewed on site in person), tier 2: $n=100$ (colour-coded according to source of information), tier 3-publications (count of objects with general counts recorded in publications colour-coded according to source of information, see table 3) and tier 3-electronic database (total count of all known geometric clay objects recovered at Neolithic Tell Sabi Abyad as recorded on the excavation database, see table 2). 

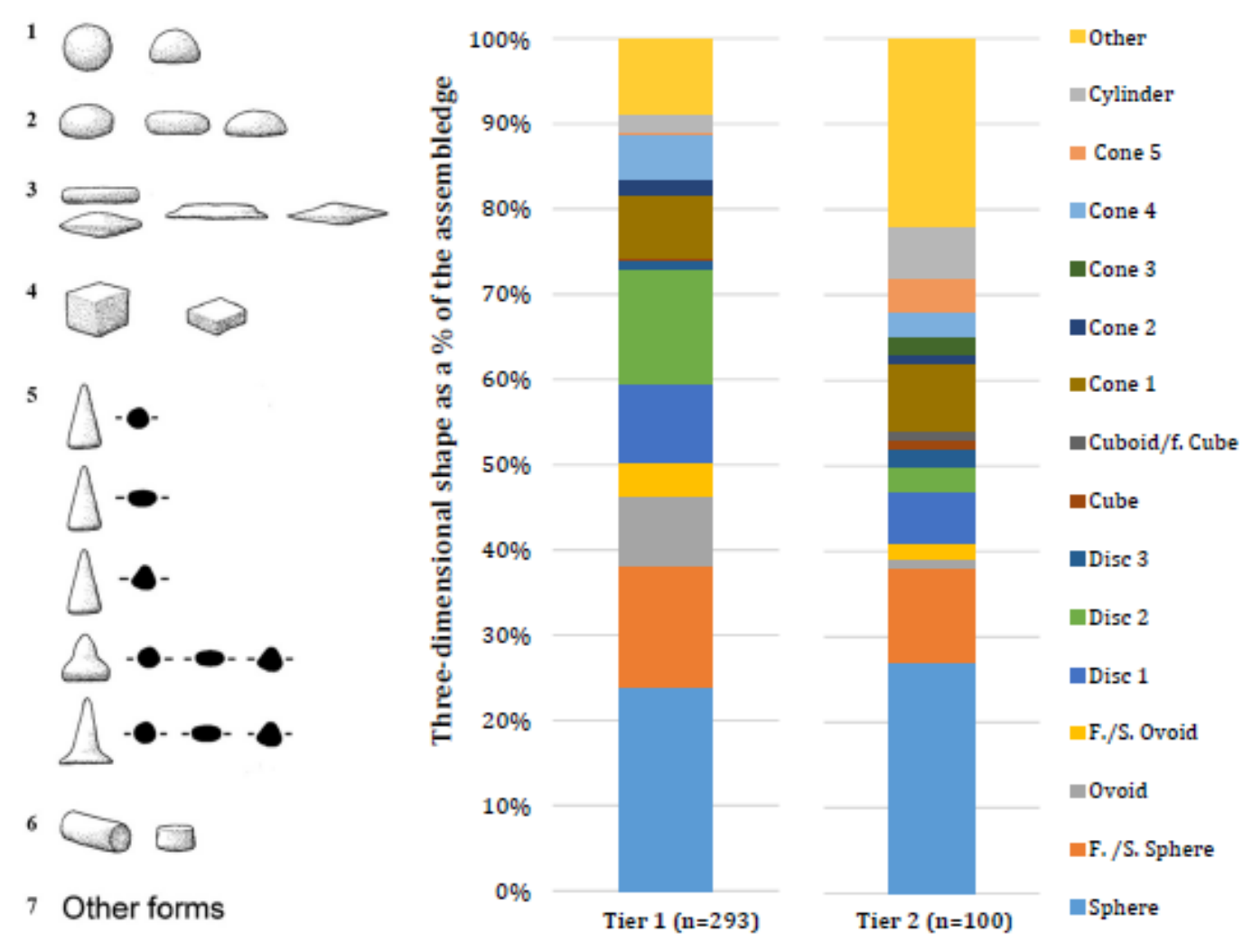

Figure 7. Left: A typological diagram illustrating the three-dimensional shape categories used in the study. (Drawings by Mesa Schumacher of the Çatalhöyük Project). Right: Chart displaying detailed three-dimensional shape as a percentage of the Tell Sabi Abyad study assemblage's total count: tier $1(n=293)$ compared to tier $2(n=100)$. 


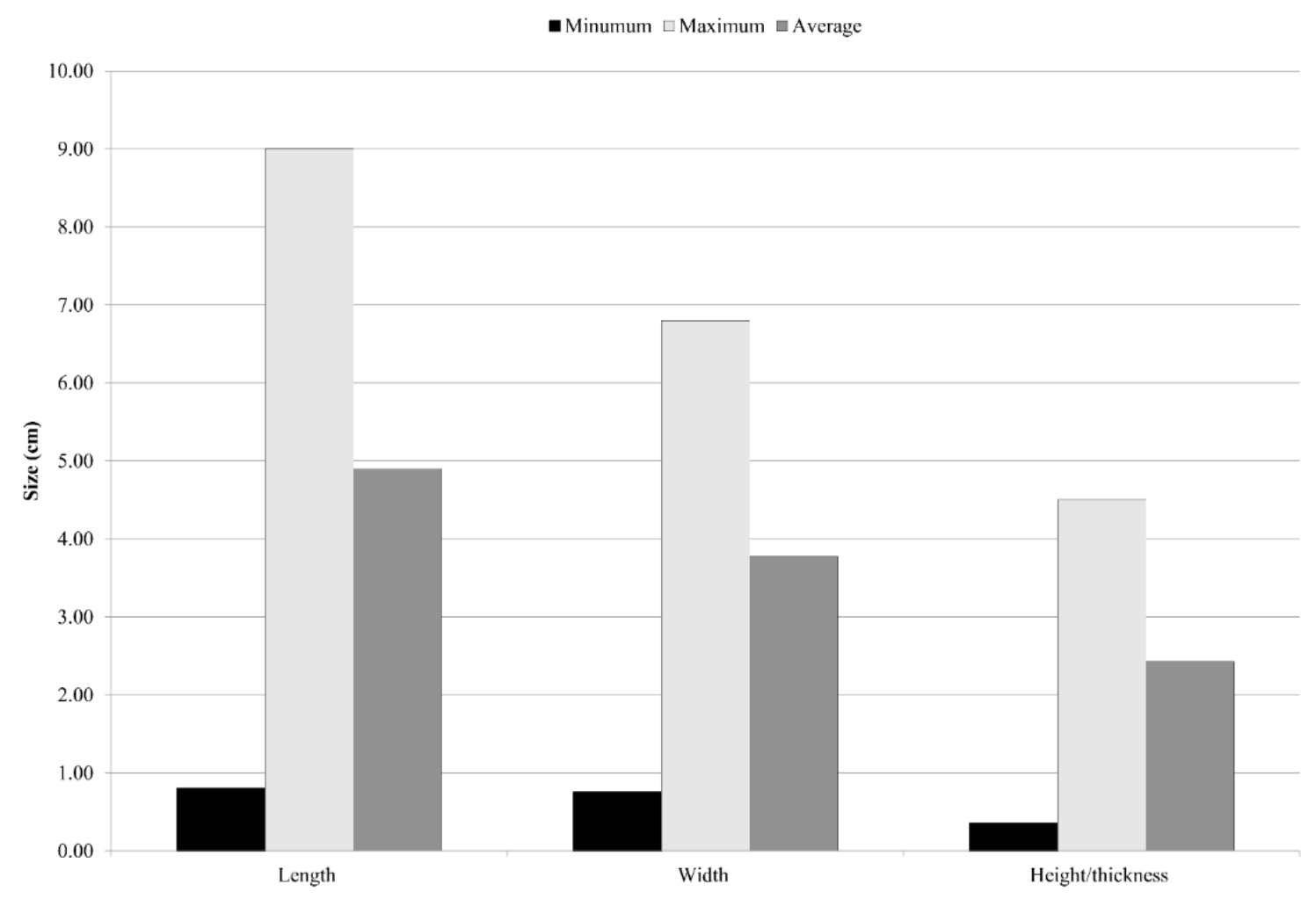

Figure 8. Average size of clay objects in three-dimensions (length, width and height/thickness) tier 1 and 2 objects combined $(n=393)$.

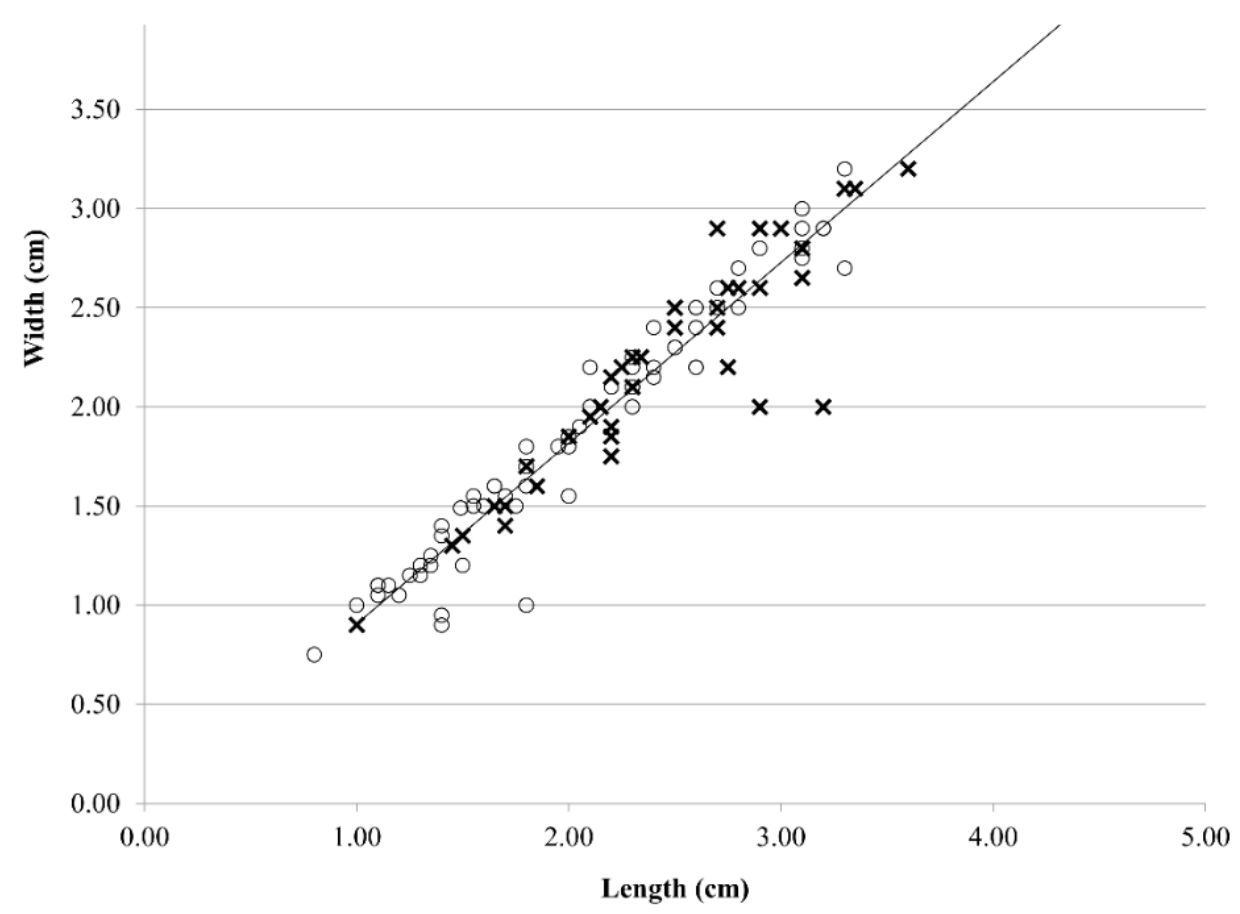

Figure 9. Tier 1 sphere and flattened/semi sphere shape size and standardisation: length vs. width comparison. 


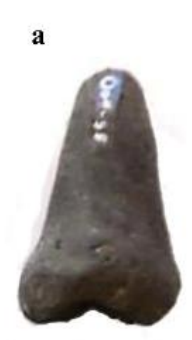

$\mathrm{cm}$

d

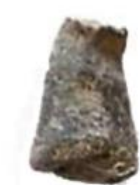

$\mathrm{cm}$ b
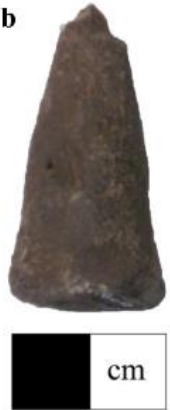

e

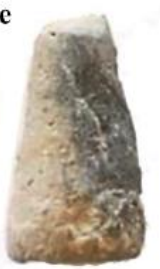

$\mathrm{cm}$ c

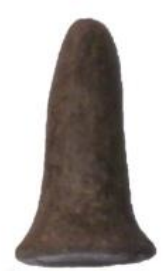

$\mathrm{cm}$

f
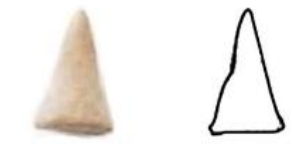

$\mathrm{cm}$

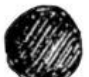

Figure 10. Figure 10. Example of the diversity of cones within and across sub-type at Tell Sabi Abyad. a. type 1 cone (round base in plan view, straight sides) with rounded tip (CO\# 270); b. type 1 come, tall, fragmented tip (CO\# 163); c. type 5 cone (flared base) displaying a tall body and rounded tip (CO\# 191); d. type 1 cone, bent upper (CO\# 268); e. type 2 cone, fragmented tip (CO\# 269); f. type 1 cone, CO\# 267 (All images/drawings, author's own).

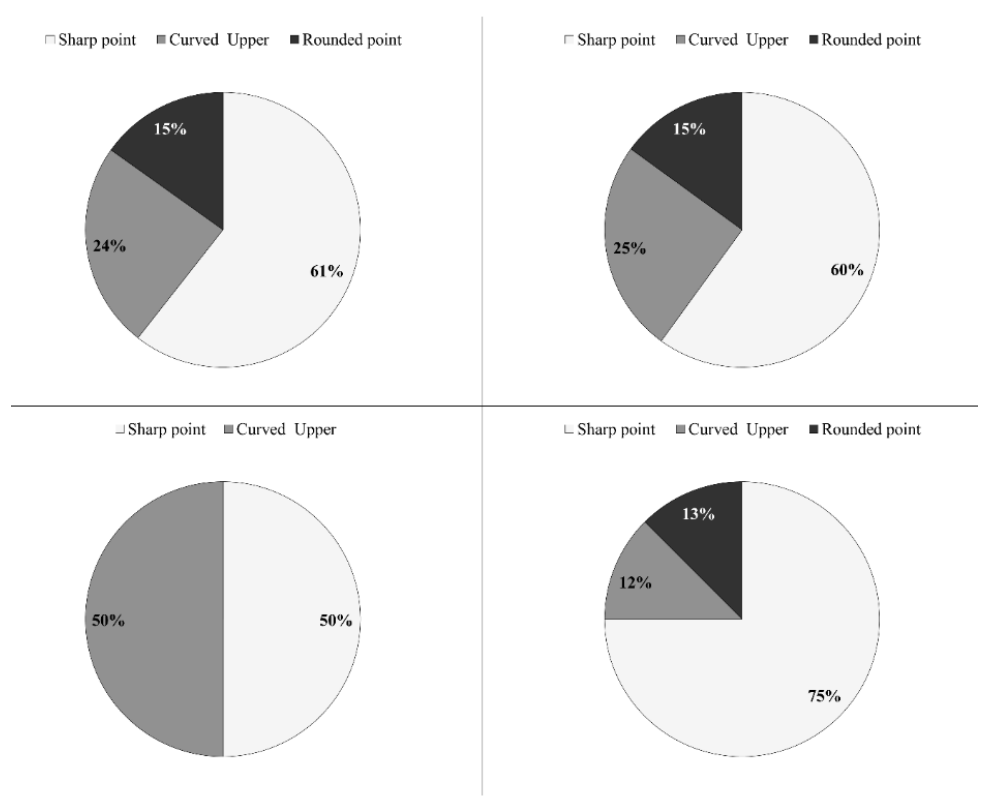

Figure 11. Tier 1 cones: diversity of tip shape according to cone sub-type. (a) all tier 1 cones combined (including the $\mathrm{n}=2$ type 5 cones: flared sides), (b) type 1 cones (round base, straight sides), (c) type 2 cones (oval base, straight sides) and (d) type 4 cones (pinched sides). 


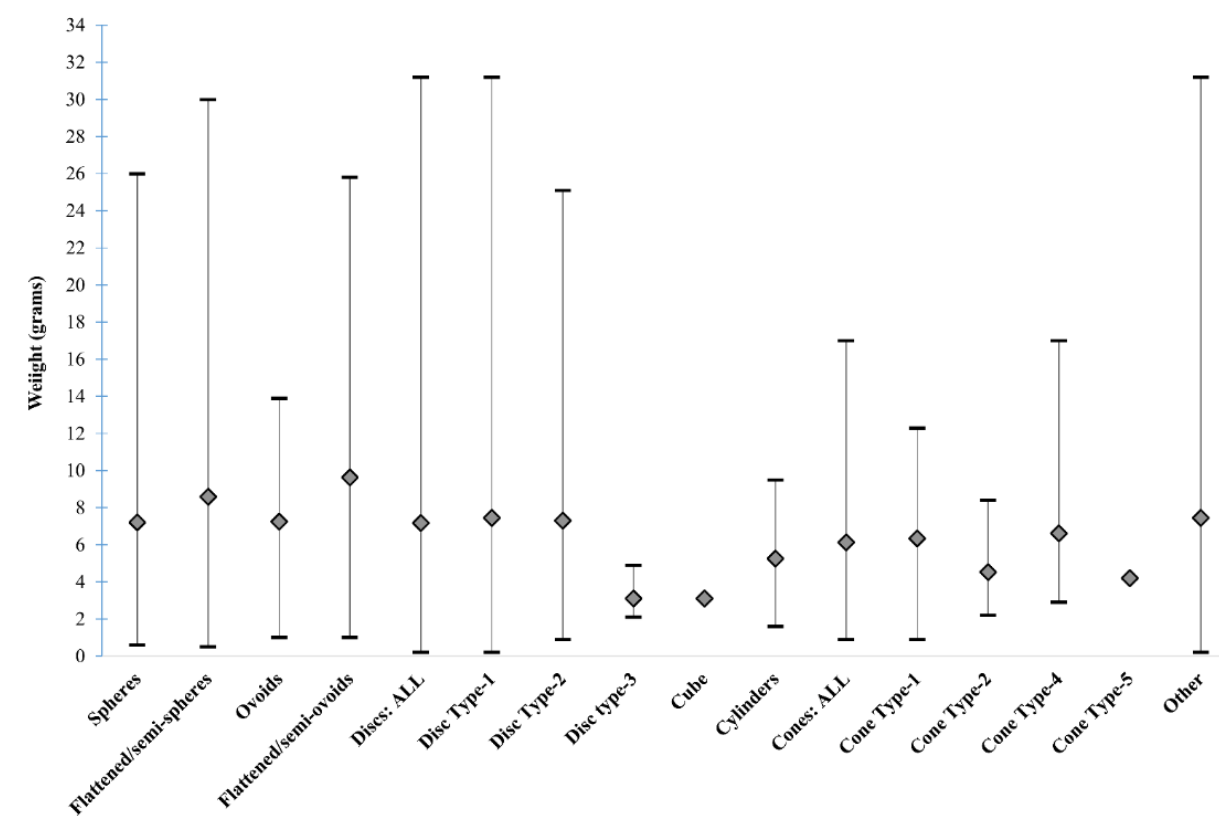

Figure 12. Weight of tier 1 clay objects by three-dimensional shape, showing the minimum (lowest marked point), maximum (highest value marked) and average (diamond) within each detailed shape category.

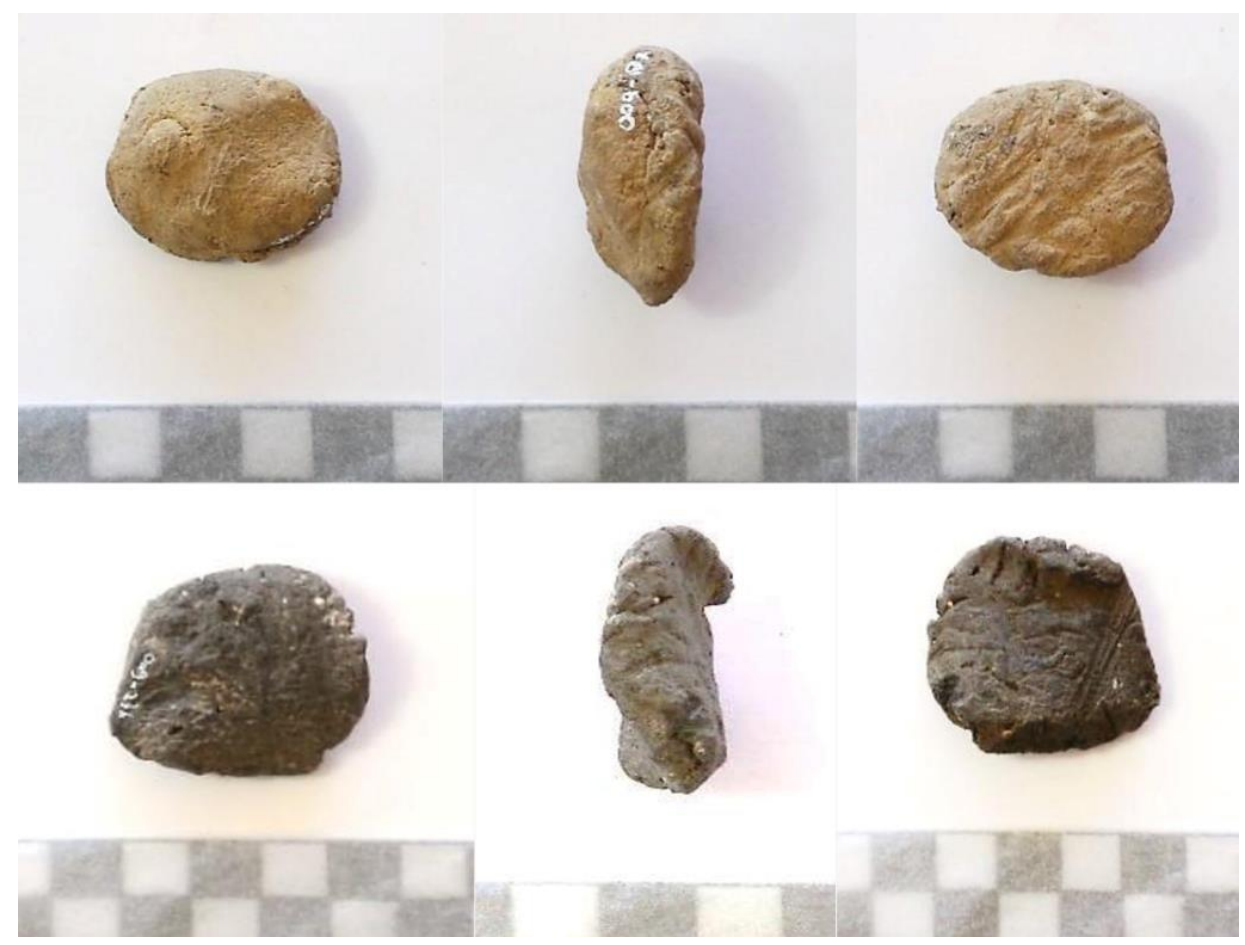

Figure 13. Discs. Top row: Type 2 (flat base) disc displaying clear evidence of the manipulation of the clay between the fingers, and the shaping of the object on a flat surface leaving impressions on the base (CO\# 309, top, section and base views). Bottom row: warped larger disc shaped object. Both sides are slightly convex and display plant impressions (CO\# 322, top, section and base views. Photograph: author's own). 

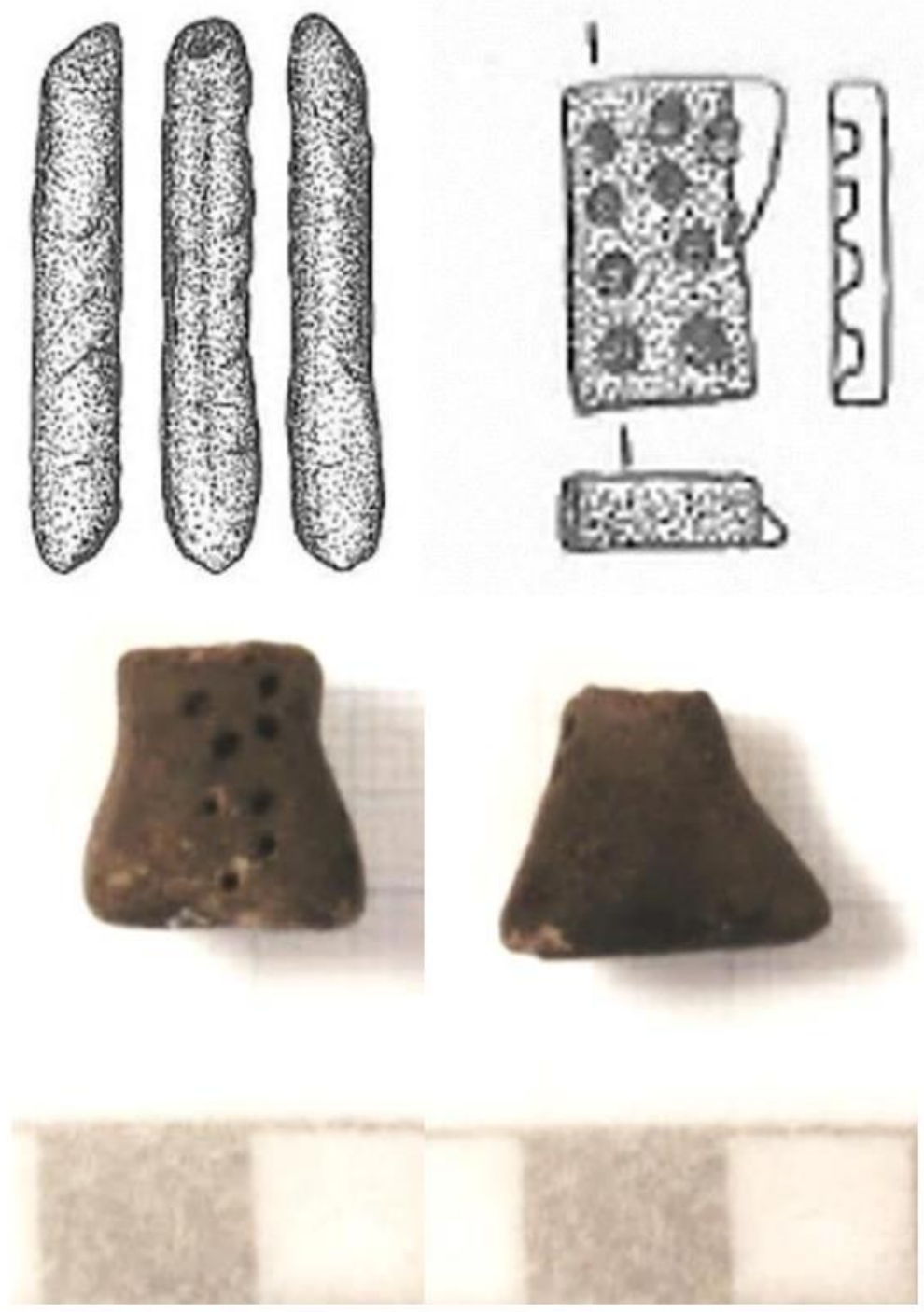

Figure 14. Marked objects. Top left: Stone cylinder with notches, tally CO\# 2911, Sabi Abyad II. (Verhoeven \& Akkermans 2000: fig. 4.7.3, p. 117, 108). Top right: A decorated clay cuboid CO\# 2912, published as a Game piece? Measures 2.90 x 2.30 x $1.50 \mathrm{~cm}$, Sabi Abyad II (Verhoeven \& Akkermans 2000: fig. 4.7.4, p. 117, 108). Bottom: CO\# 226, truncated clay cone with markings (front and back views). (Photographs: author's own). 

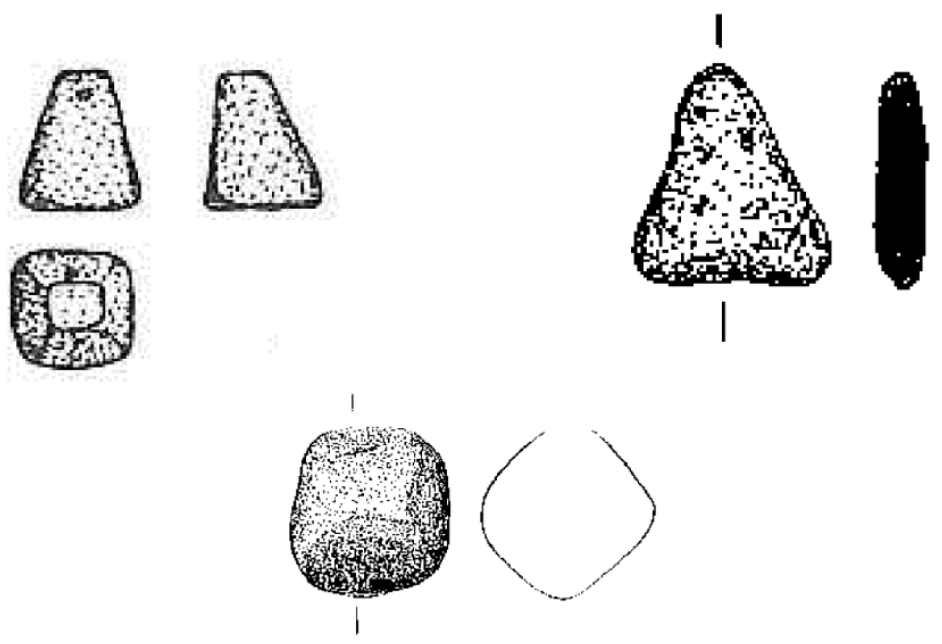

Figure 15. Stone geometric-shaped objects from Tell Sabi Abyad (tier 2). Top left: CO\# 2879: whitish stone (gypsum or rock-crystal) type 3 cone with square base. $1.20 \times 1.00 \times 1.00 \mathrm{~cm}$ (Akkermans 1996b: fig. 8.5.5, p. 466). Top right: CO\# 2880: two dimensional triangle, $1.80 \mathrm{x}$ 1.60 x $0.40 \mathrm{~cm}$ (Akkermans 1996b: fig. 8.5.6, p. 466). Bottom centre: CO\# 2914: cube-shaped limestone object, 3.10 x $3.00 \times 3.00 \mathrm{~cm}$ (Verhoeven \& Akkermans 2000: fig. 4.7.6, p. 117).

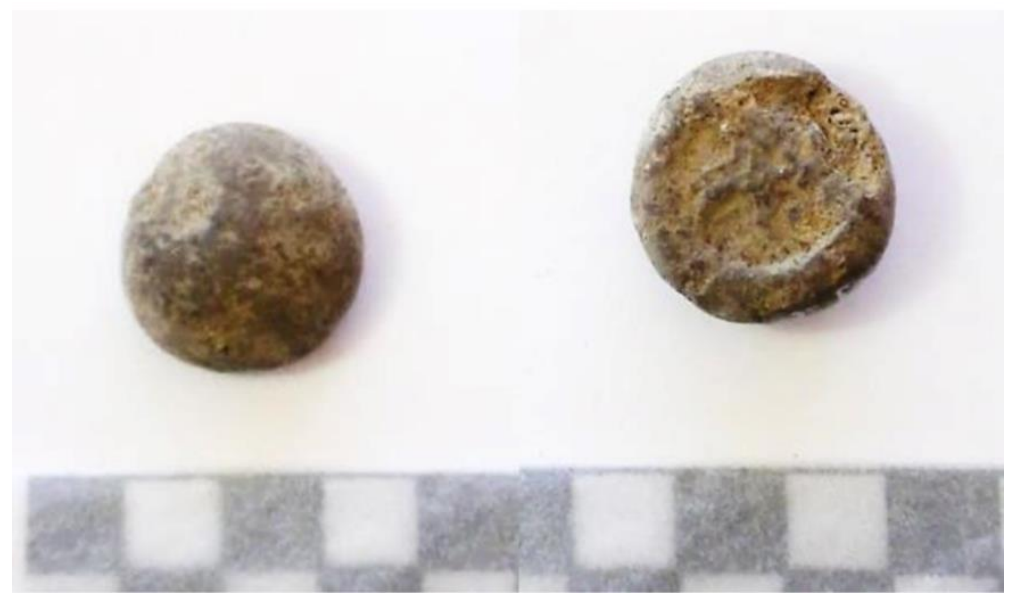

Figure 16.Semi-spherical clay object CO\# 287 (tier 1) with a probable stamp seal impression on the base. Measures 2.50 x 8.40 x $1.40 \mathrm{~cm}$ (diameter/circumference/thickness). Late Neolithic (c. 6,900-5,700 BC) phase, operation III, Tell Sabi Abyad I (Photograph: author's own, top and base views). 


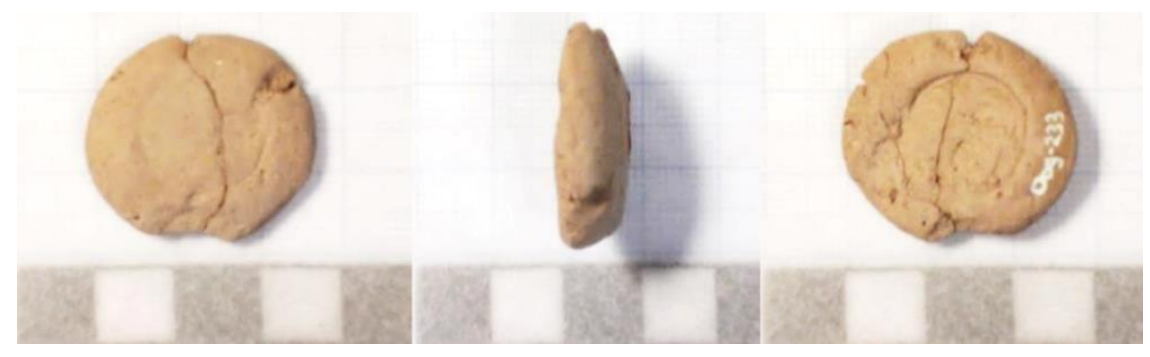

Figure 17. CO\# 105, a disc stamped on both sides. Top, section and base views depicted. Dimensions: 2.80 × $2.60 \times 1.80 \mathrm{~cm}$ (length/width/thickness), circumference $8.60 \mathrm{~cm}$. Late Neolithic, operation III, Tell Sabi Abyad I. (Photograph: author's own). 

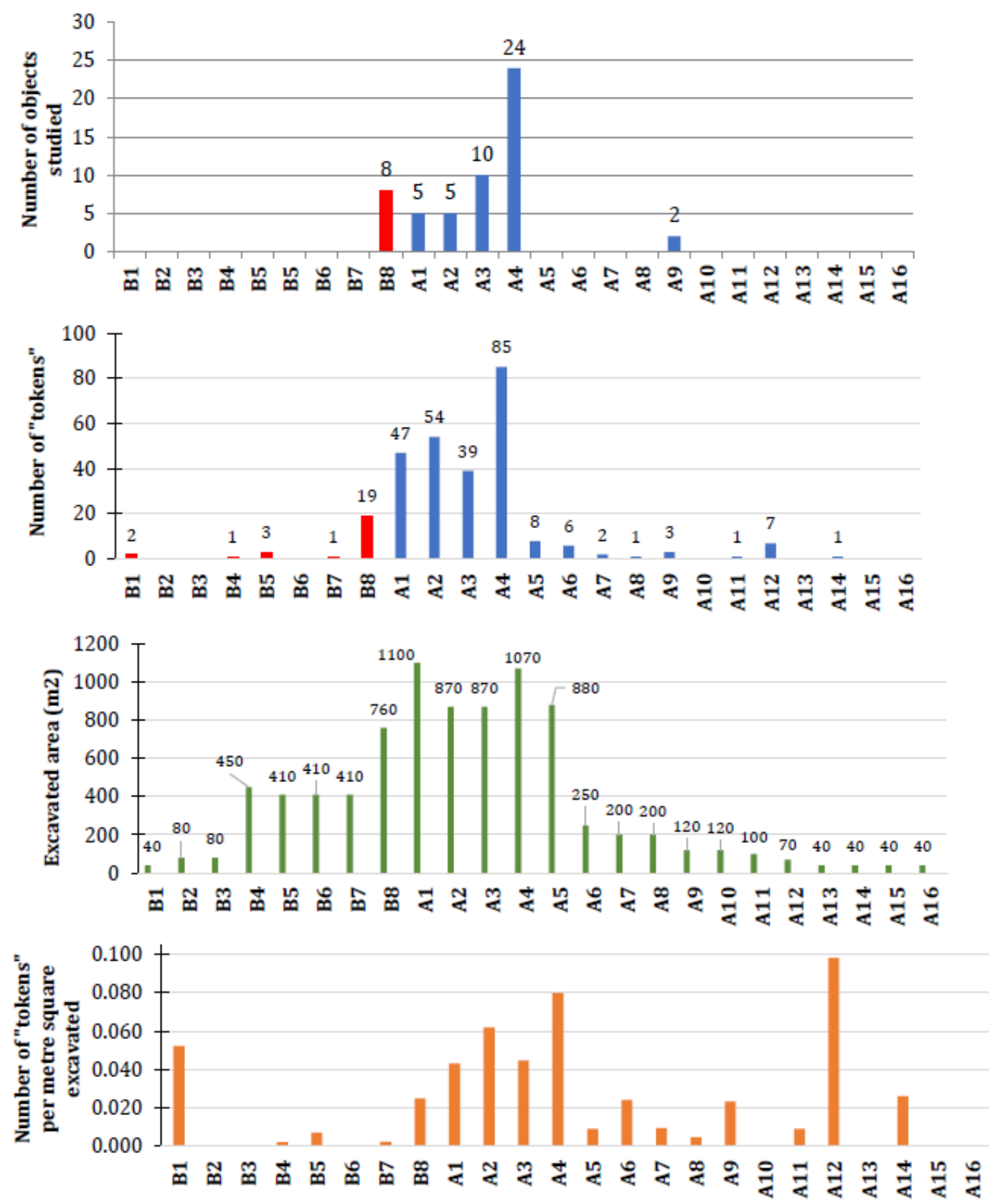

Figure 18. The temporal distribution of geometric clay objects within operation III's stratigraphic sequence, arranged left to right from youngest (level B1, c. 6,000 BC) to oldest (level A16, c. 7,000 BC). Top: Objects studied in person (tier 1). Second: All known excavated clay objects (artefacts registered on site as tokens). Third: Area excavated (metres squared) per level (Tell Sabi Abyad Research Project). Bottom: The number of objects excavated per approximate $\mathrm{m}^{2}$ of excavation within each level. 


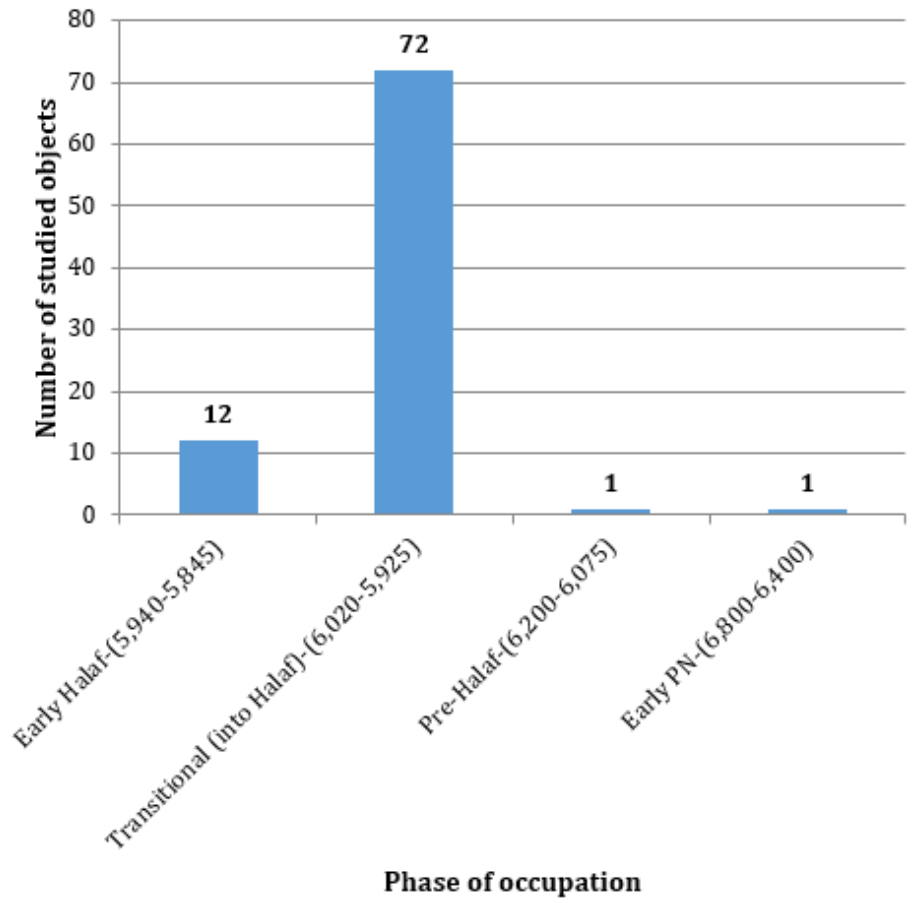

Figure 19. The temporal distribution by cultural phase, of all 86 clay objects recorded (all at tier 2 level) from operation I, Tell Sabi Abyad I. 


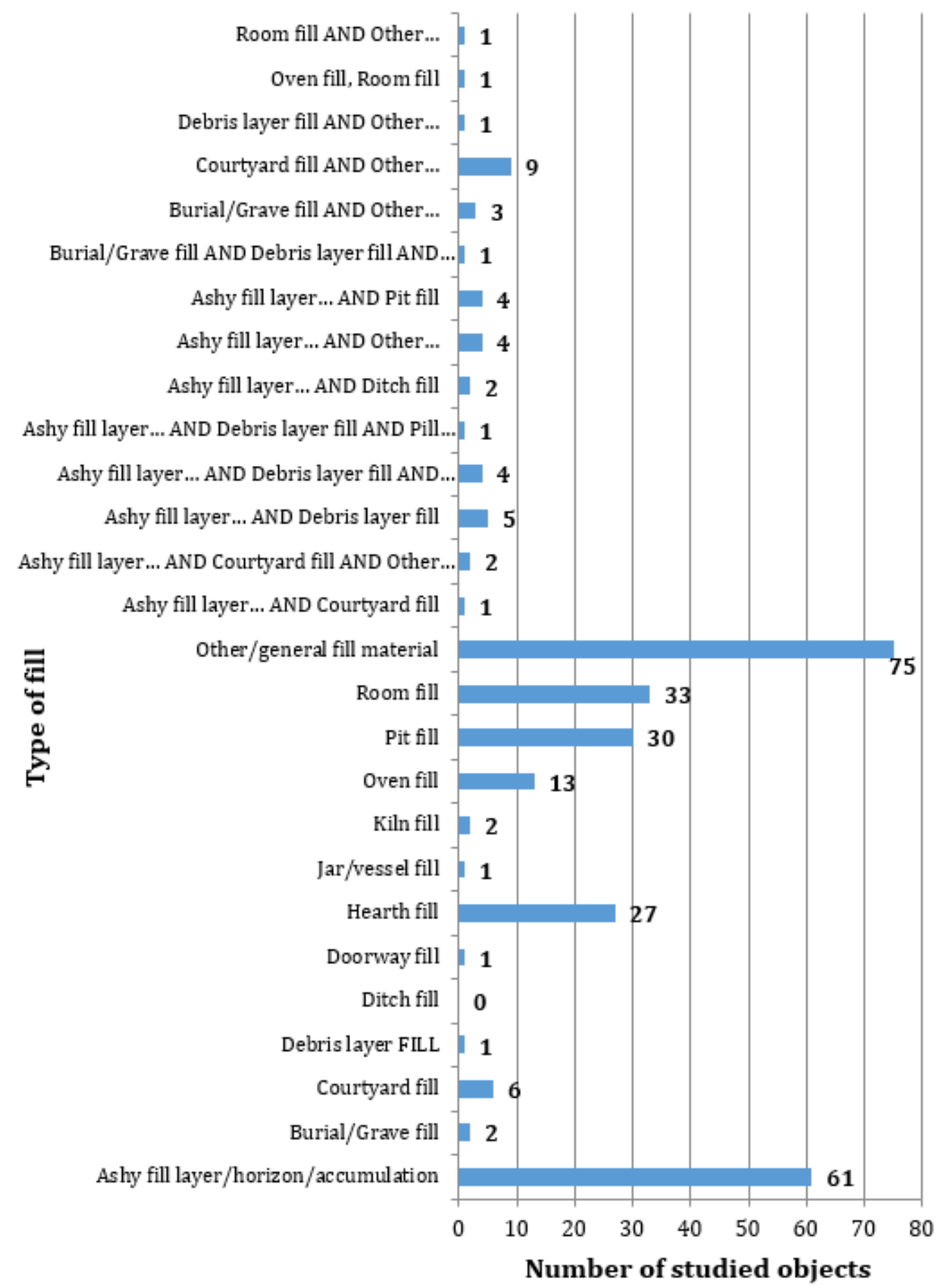

Figure 20. Detail of the studied small geometric clay objects which come from fill context types (74\%, $n=291$ of the tier 1 assemblage). 


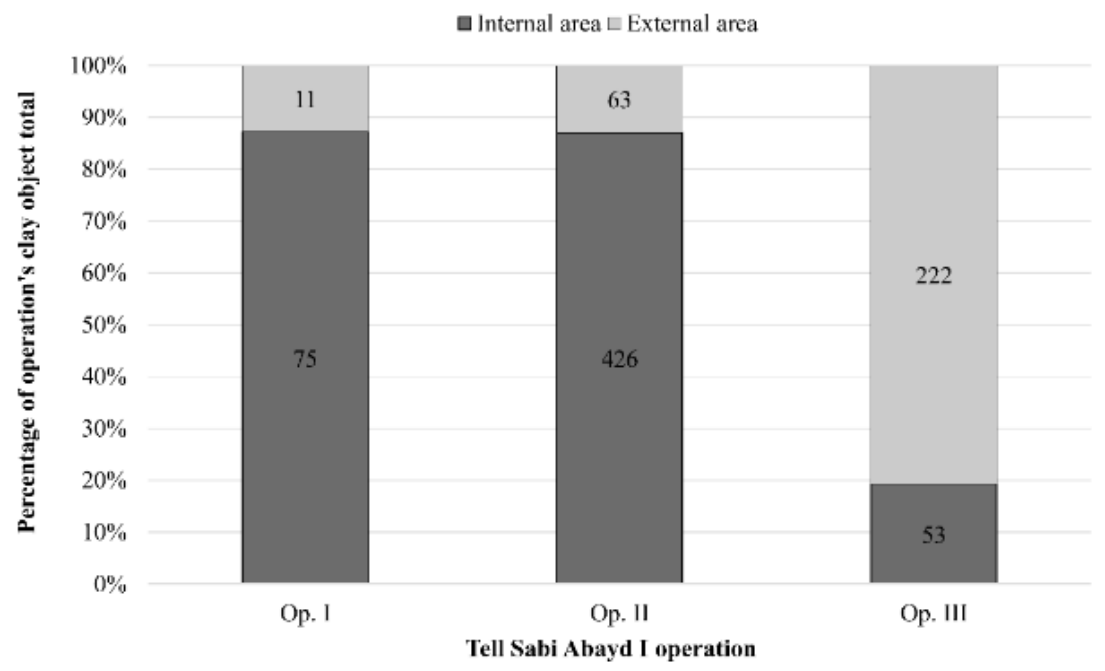

Figure 21. Broad context of clay objects: internal vs. external areas across the different occupational zones of Tell Sabi Abyad I (Operations I and III tier 1 and 1 data, Operation II tier 3 data).

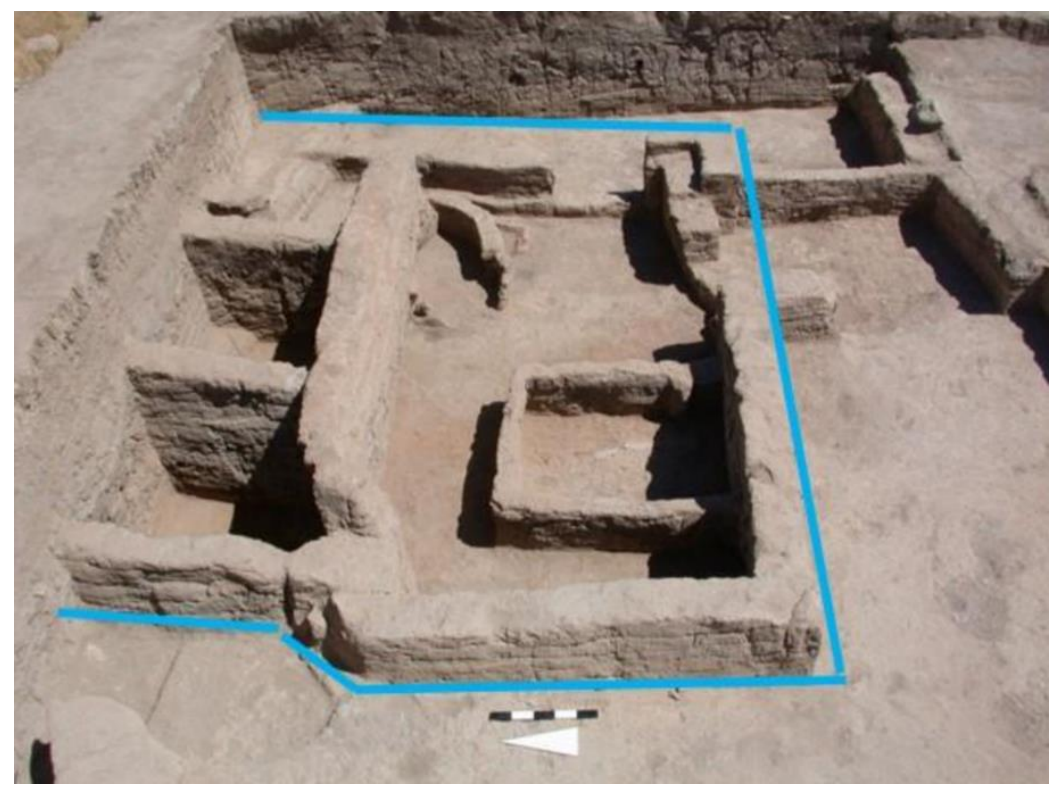

Figure 22. View of operation II from the west, looking east, showing the location and extent of the level 2 T-shaped building within the upper occupation sequence $(6,000-5,800 \mathrm{BC})$. Room 2 is the square room in the bottom left corner, measuring approximately $1.25 \times 1.25 \mathrm{~m}^{2}$. This room was full of small geometric shaped clay objects and was heavily burnt throughout. (Photo courtesy of the Tell Sabi Abyad Project). 

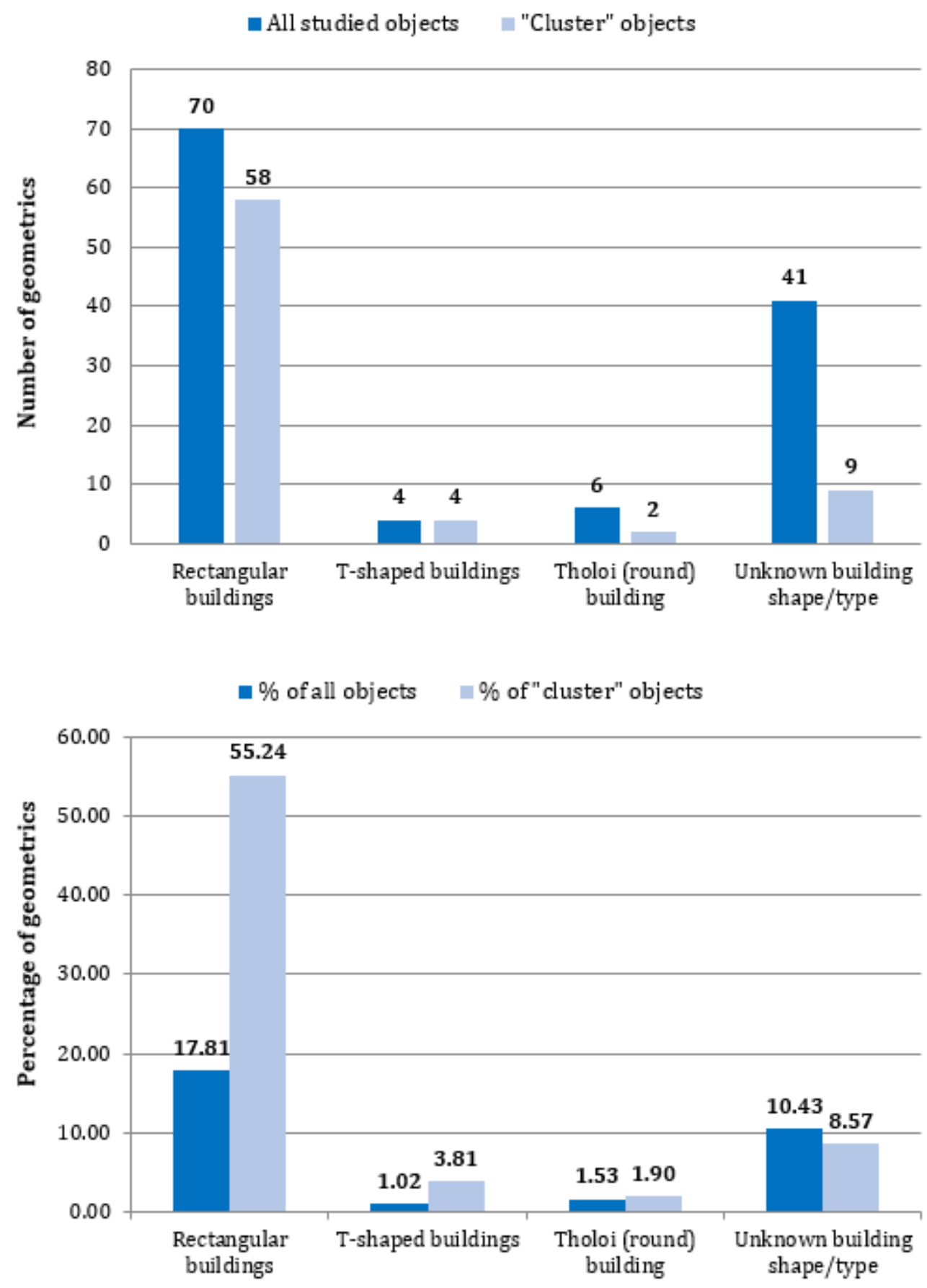

Figure 23. Comparison of the building shape of those geometric clay objects recovered from buildings, classified by building type. 


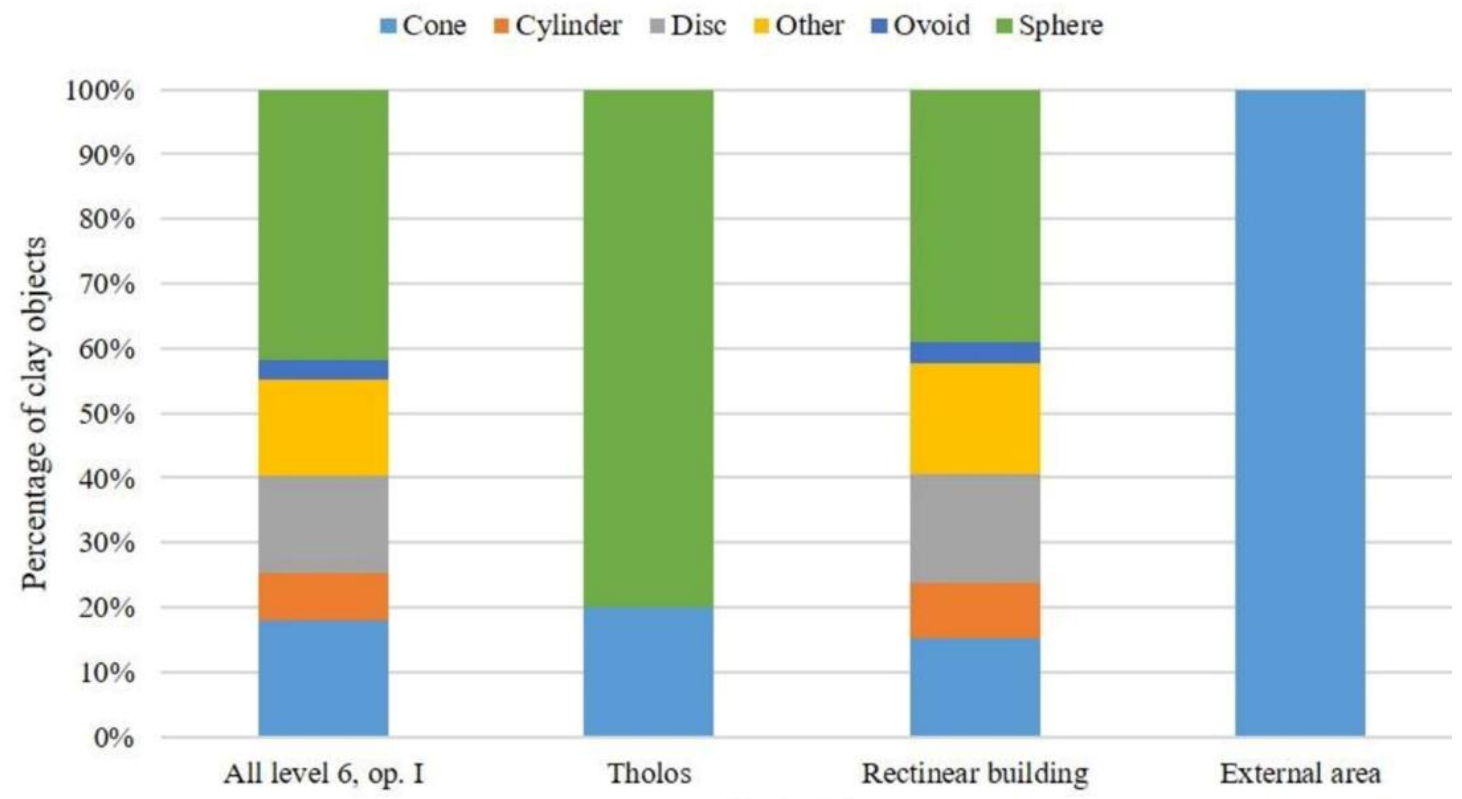

Figure 24. The distribution of geometric clay objects by basic three-dimensional shape. All level 6 , operation I clay objects combined $(n=67)$ contrasted to level 6 clay objects by context type: tholos, rectilinear building and all external space contexts combined. 
Table 1. Range of clay artefact types common in the late Neolithic Near East; terminology and definitions/functional classification.

\section{TERM}

Clay artefact

Clay object

Figurine

Sealing

Sling-missile

Pot-sherd disc

Stamp-seal

Bead

Labret

Pottery

\section{DESCRIPTION}

Broad term used to refer to any of the artefact types listed below.

Small ( $<5 \mathrm{~cm}$ maximum dimension), intentionally crafted, artefact of a clear geometric form. Maybe decorated or plain. Comparable objects of manufactured stone are also included.

Human or animal representation in three-dimensions.

A lump of clay, pressed onto a container opening to close it, or secured around a package/bundle. Often marked with a stamp seal impression

A projectile weapon. At Sabi Abyad, sling-missiles are recovered in caches in their hundreds. Homogenous in size ( $>5 \mathrm{~cm}$ length), clay colour, finish and shape, the elongate-spheroids are distinct in appearance. They are not easily confused with clay objects. (pottery sherds shaped into a circular form, pierce red or unpierced in the centre, likely acting as lids for containers)

Small shaped object (of clay, stone, bone or other material) with one flat surface decorated with a naturalistic or abstract design. Used as a stamp to mark property or ownership.

Small, pierced piece of various shapes (sphere, slender, cuboid), threaded with other similar pieces to form a necklace, bracelet or other piece of jewellery.

Elongated cone or nail-shaped ornament, inserted into the lip. Worn as jewellery.

A container/vessel of any form, made from fired clay. Can be used for storage, food/drink serving or purely decorative. 
Table 2. The estimated total number of recovered clay geometrics at Tell Sabi Abyad (all tells and operations combined). Simplified version of the Tell Sabi Abyad digitised small finds database: count of Neolithic contexts only, filtered by object designation, size (objects $<5 \mathrm{~cm}$ only), raw material (clay objects only) and separated by excavation season.

\begin{tabular}{|c|c|c|c|c|c|c|c|c|c|c|c|c|c|c|c|c|c|c|c|}
\hline DESIGNATION & $\stackrel{\circ}{2}$ & $\stackrel{\infty}{\infty}$ & $\bar{\sigma}$ & $\tilde{\sigma}$ & $\tilde{\sigma}$ & $\stackrel{2}{2}$ & $\hat{\sigma}$ & $\stackrel{\infty}{\sigma}$ & बे & 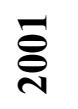 & 气ั̊ & 气̊̊̆ & 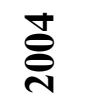 & 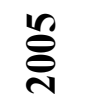 & $\hat{\mathscr{\vartheta}}$ & 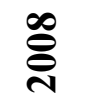 & ڤ્̀ે & 율 & $\begin{array}{c}\text { ALL } \\
\text { SEASONS }\end{array}$ \\
\hline 'Ball' & 0 & 0 & 0 & 0 & 0 & 0 & 0 & 1 & 0 & 1 & 0 & 0 & 0 & 1 & 0 & 0 & 0 & 0 & 3 \\
\hline 'Bulla' & 0 & 0 & 0 & 0 & 0 & 0 & 0 & 0 & 0 & 0 & 0 & 0 & 4 & 0 & 0 & 0 & 0 & 0 & 4 \\
\hline $\begin{array}{l}\text { 'Lump' / 'Lumps' / 'Lump } \\
\text { (token)' / 'Fingerprint' }\end{array}$ & 0 & 0 & 0 & 0 & 0 & 0 & 16 & 27 & 25 & 0 & 5 & 12 & 72 & 0 & 47 & 0 & 5 & 0 & 209 \\
\hline 'Shaped clay' & 0 & 0 & 0 & 0 & 0 & 0 & 0 & 0 & 0 & 0 & 0 & 0 & 0 & 23 & 0 & 0 & 0 & 0 & 23 \\
\hline 'Clay object' & 0 & 0 & 0 & 0 & 0 & 0 & 0 & 0 & 0 & 0 & 0 & 0 & 0 & 0 & 0 & 0 & 0 & 29 & 29 \\
\hline 'Unknown' (clay artefact) & 0 & 0 & 0 & 0 & 0 & 0 & 0 & 0 & 0 & 0 & 0 & 0 & 0 & 0 & 0 & 0 & 0 & 3 & 3 \\
\hline 'Miniature bowl' & 0 & 3 & 7 & 1 & 0 & 2 & 0 & 0 & 1 & 0 & 6 & 0 & 1 & 3 & 0 & 1 & 0 & 0 & 25 \\
\hline 'Miniature jar' & 2 & 2 & 0 & 3 & 1 & 2 & 0 & 0 & 1 & 0 & 0 & 0 & 0 & 0 & 2 & 0 & 0 & 0 & 13 \\
\hline 'Miniature vessel' & 0 & 0 & 0 & 0 & 0 & 0 & 0 & 0 & 0 & 1 & 0 & 1 & 5 & 1 & 4 & 0 & 0 & 0 & 12 \\
\hline ‘Tally?’ & 0 & 0 & 0 & 0 & 1 & 0 & 0 & 0 & 0 & 0 & 0 & 0 & 0 & 0 & 0 & 0 & 0 & 0 & 1 \\
\hline 'Token/Token?' & $\mathbf{0}$ & 14 & 69 & 58 & 40 & 49 & 80 & 67 & 64 & 25 & 30 & 32 & 157 & 66 & 168 & 112 & 137 & 9 & 1,177 \\
\hline 'Token/labret' & 0 & 0 & 0 & 0 & 0 & 0 & 0 & 0 & 0 & 0 & 0 & 0 & 1 & 2 & 3 & 2 & 1 & 0 & 9 \\
\hline 'Token/sling missile' & 0 & 0 & 0 & 0 & 0 & 0 & 0 & 0 & 0 & 0 & 0 & 0 & 2 & 0 & 0 & 0 & 0 & 0 & 2 \\
\hline 'Token/figurine' & 0 & 0 & 0 & 0 & 0 & 0 & 0 & 0 & 0 & 0 & 0 & 0 & 1 & 11 & 7 & 5 & 1 & 0 & 25 \\
\hline TOTAL & 2 & 19 & 76 & 62 & 42 & 53 & 96 & 95 & 91 & 27 & 41 & 45 & 243 & 107 & 231 & 120 & 144 & 41 & 1,535 \\
\hline
\end{tabular}


Table 3. Detail of the clay objects studied at tier 3 level (total number of 'tokens' referred to in passing, and with general references only) -those from publications only. Tier 3 clay objects come from three publications, and can be organised according to occupation level within operation I of the main tell, and Tell Sabi Abyad II. (Note: 'Cultural Phase' terminology and dates represent approximate years cal. BC according to level as published by Akkermans et al. 2014: tables 1.2 p. 26, .3 p. 28 \& 2.2 p. 31 and Akkermans \& Verhoeven 2000: p. 1, fig. 4.3 p. 93 as amended in Akkermans at al. 2014: tables $2.1 \& 2.2$ p. 31).

\begin{tabular}{|c|c|c|c|c|c|c|c|}
\hline $\begin{array}{c}\text { SOURCE } \\
\text { (excavation seasons } \\
\text { covered) }\end{array}$ & TELL & $\begin{array}{c}\text { OPERATION } \\
\text { (Tell Sabi } \\
\text { Abyad I only) }\end{array}$ & $\begin{array}{c}\text { STRATIGR } \\
\text { APHIC } \\
\underline{L E V E L} \\
\end{array}$ & $\begin{array}{c}\text { TOKENS } \\
\text { PER } \\
\text { LEVEL }\end{array}$ & CULTURAL $\underline{P H A S E}$ & $\begin{array}{c}\text { TOTAL } \\
\text { NUMBER } \\
\text { OF } \\
\text { 'TOKENS' } \\
\text { (RECORDED } \\
\text { AT TIER 3) }\end{array}$ & $\begin{array}{c}\text { OF WHICH ARE } \\
\text { INDIVIDUALLY } \\
\text { ILLUSTRATED } \\
\text { (RECORDED AT TIER } \\
2 \text { LEVEL) }\end{array}$ \\
\hline \multirow[t]{6}{*}{$\begin{array}{l}\text { Akkermans 1996b } \\
(1988-1993)\end{array}$} & $\begin{array}{l}\text { Tell Sabi } \\
\text { Abyad I }\end{array}$ & Operation I & 8 & 1 & $\begin{array}{l}\text { Pre-Halaf, } \\
6,200-6,075\end{array}$ & & \\
\hline & & & 7 & 0 & & & \\
\hline & & & 6 & $\begin{array}{r}167 \\
4\end{array}$ & $\begin{array}{l}\text { Transitional Halaf, } \\
6,020-5,925\end{array}$ & & \\
\hline & & & 4 & 8 & & & \\
\hline & & & $3 \mathrm{~B}$ & 17 & $\begin{array}{l}\text { Early Halaf, } \\
\text { c. } 5,940-5,845\end{array}$ & & \\
\hline & & & $\begin{array}{l}\text { ALL } \\
\text { LEVELS } \\
\text { TOTAL: }\end{array}$ & 197 & $\begin{array}{l}\text { Pre-Halaf to Early Halaf } \\
\text { c. } 6,200-5,845\end{array}$ & 197 & 55 \\
\hline $\begin{array}{l}\text { Verhoeven } 1999 \\
(1986-1993)\end{array}$ & $\begin{array}{l}\text { Tell Sabi } \\
\text { Abyad I }\end{array}$ & Operation I & 6 & 182 & $\begin{array}{l}\text { Transitional Halaf, } \\
6,020-5,925\end{array}$ & 182 & 0 \\
\hline $\begin{array}{l}\text { Akkermans \& } \\
\text { Verhoeven } 2000\end{array}$ & $\begin{array}{l}\text { Tell Sabi } \\
\text { Abyad II }\end{array}$ & - & 7 & 4 & PPNB & 19 & 5 \\
\hline
\end{tabular}




\begin{tabular}{|c|c|c|c|c|c|c|}
\hline & & 5 & 3 & PPNB & & $\begin{array}{l}\text { (plus } 5 \text { objects of } \\
\text { other designations) }\end{array}$ \\
\hline & & 3 & 9 & PPNB & & \\
\hline & & 2 & 1 & PPNB & & \\
\hline & & 1 & 2 & $\begin{array}{l}\text { Ceramic Neolithic } \\
\text { (exact period uncertain) }\end{array}$ & & \\
\hline & & $\begin{array}{l}\text { ALL } \\
\text { LEVELS } \\
\text { TOTAL: }\end{array}$ & 19 & - & & \\
\hline $\begin{array}{l}\text { Tell Sabi } \\
\text { Abyad I }\end{array}$ & Operation II & $\begin{array}{l}\text { 'Upper' } \\
\text { sequence }\end{array}$ & Hundreds & $\begin{array}{l}\text { Transitional Halaf, } \\
6,020-5,925\end{array}$ & 'Hundreds' & 0 \\
\hline $\begin{array}{l}\text { Tell Sabi } \\
\text { Abyad I }\end{array}$ & Operation II & $\begin{array}{l}\text {-'Lower' } \\
\text { sequence }\end{array}$ & 57 & $\begin{array}{l}\text { Transitional Halaf, } \\
6,020-5,925\end{array}$ & 57 & 0 \\
\hline $\begin{array}{l}\text { Tell Sabi } \\
\text { Abyad I }\end{array}$ & Operation I & $\begin{array}{l}\text { ALL } \\
\text { LEVELS } \\
\text { TOTAL }\end{array}$ & 297 & $\begin{array}{l}\text { Pre-Halaf to Early Halaf } \\
\text { c. } 6,200-5,845\end{array}$ & 297 & 0 \\
\hline
\end{tabular}

Akkermans et al. 2006 (2002, 2003)

Akkermans et al. 2012 (2004)

Akkermans et al. 2014 (1994-1999) 
Table 4. A list of clay obejcts by three-dimensional shape and presence/absence of markings: tier 1 Tell Sabi Abyad clay objects $(n=293)$.

\begin{tabular}{|c|c|c|c|c|c|c|}
\hline $\begin{array}{c}\text { THREE } \\
\text { DIMENSIONAL } \\
\text { SHAPE }\end{array}$ & TOTAL & $\begin{array}{c}\% \text { OF ALL } \\
\text { SAB CLAY } \\
\text { OBJECTS }\end{array}$ & $\begin{array}{c}\text { NO. OF } \\
\text { MARKED } \\
\text { OBJECTS }\end{array}$ & $\begin{array}{c}\% \text { OF ALL } \\
\text { MARKED } \\
\text { OBJECTS } \\
(n=111)\end{array}$ & $\begin{array}{c}\% \text { OF } \\
\text { SHAPES } \\
\text { ASSEMBL } \\
\text { AGE } \\
\text { MARKED }\end{array}$ & $\begin{array}{c}\text { NO. OF } \\
\text { OBJECTS } \\
\text { UNMARKED } \\
\text { WITHIN } \\
\text { SHAPE }\end{array}$ \\
\hline Sphere & 70 & $23 \%$ & 16 & $14 \%$ & $23 \%$ & 54 \\
\hline F. /S. Sphere & 14 & $14 \%$ & 17 & $15 \%$ & $40 \%$ & 25 \\
\hline Ovoid & 24 & $8 \%$ & 6 & $5 \%$ & $25 \%$ & 18 \\
\hline F./S. Ovoid & 11 & $4 \%$ & 5 & $4.50 \%$ & $45 \%$ & 6 \\
\hline Disc Type 1 & 27 & $9 \%$ & 17 & $15 \%$ & $63 \%$ & 10 \\
\hline Disc Type 2 & 40 & $14 \%$ & 23 & $20.72 \%$ & $58 \%$ & 17 \\
\hline Disc Type 3 & 3 & $1 \%$ & 1 & $<1 \%$ & $33 \%$ & 2 \\
\hline Discs combined & 70 & $24 \%$ & 41 & $36.94 \%$ & $59 \%$ & 29 \\
\hline Cube & $\mathbf{1}$ & $<1 \%$ & $\mathbf{0}$ & $0.00 \%$ & $0 \%$ & 1 \\
\hline Cone Type 1 & 21 & $7 \%$ & 6 & $5 \%$ & $29 \%$ & 15 \\
\hline Cone Type 2 & 6 & $2 \%$ & 1 & $<0 \%$ & $17 \%$ & 5 \\
\hline Cone Type 4 & 15 & $5 \%$ & 9 & $8 \%$ & $60 \%$ & 6 \\
\hline Cone Type 5 & 1 & $<1 \%$ & $\mathbf{0}$ & $0 \%$ & $0 \%$ & 1 \\
\hline Cones combined & 43 & $15 \%$ & 16 & $14 \%$ & $37 \%$ & 27 \\
\hline Cylinder & 6 & $2 \%$ & $\mathbf{0}$ & $0 \%$ & $0 \%$ & 6 \\
\hline Other/misc. & 26 & $9 \%$ & 10 & $9 \%$ & $38 \%$ & 16 \\
\hline TOTAL & 293 & $100 \%$ & 111 & - & - & - \\
\hline
\end{tabular}


Table 5. Texture and finish of the $n=293$ tier 1 clay objects.

\begin{tabular}{lcc}
\hline CLAY TEXTURE & COUNT & $\%$ \\
\hline Coarse & & \\
Fine & 11 & 3.75 \\
Unsure & 277 & 94.54 \\
n/a (not clay) & 4 & 1.37 \\
\hline ORIGINAL SURFACE FINISH & COUNT & $\% .34$ \\
\hline Rough & 34 & 11.60 \\
Smooth & 208 & 70.99 \\
Very Smooth & 46 & 15.70 \\
Rough/Smooth (combination) & 5 & 1.71 \\
\hline
\end{tabular}

Table 6. Detail of the $n=9$ (9\%) of tier 2 clay objects with intentional markings.

\begin{tabular}{lll}
\hline $\mathbf{C O \#}$ & 3D SHAPE & MARKINGS BASIC FORM PRESENCE \\
\hline $\mathbf{2 8 2 8}$ & Flattened/semi-sphere & Type 7: Round Depression(s) \\
$\mathbf{2 8 5 1}$ & Sphere & Type 1 : Straight, Independent Line(s) \\
$\mathbf{2 8 5 2}$ & Flattened/semi-ovoid & Type 1 : Straight, Independent Line(s) \\
$\mathbf{2 8 6 1}$ & Flattened/semi-sphere & Type 1: Straight, Independent Line(s) \\
$\mathbf{2 8 6 2}$ & Flattened/semi-sphere & Type 1: Straight, Independent Line(s) \\
$\mathbf{2 8 6 5}$ & Flattened/semi-sphere & Type 1: Straight, Independent Line(s) \\
$\mathbf{2 9 1 1}$ & Cylinder & Type 1: Straight, Independent Line(s), Type 2: Straight Parallel Lines \\
$\mathbf{2 9 1 2}$ & Cuboid & Type 7: Round Depression(s), possible stamp seal \\
$\mathbf{2 9 1 6}$ & Sphere & Type 1: Straight, Independent Line(s) \\
\hline
\end{tabular}


Table 7. The number of individually studied small geometric clay objects (tier 1-individually in person and tier 2-individually via publications and unpublished archives) by phase of occupation (detailed and broad 'cultural' phase).

\begin{tabular}{|c|c|c|c|c|c|}
\hline & $\begin{array}{l}\text { CULTURAL PHASE } \\
\text { (youngest to oldest) }\end{array}$ & $\begin{array}{l}\text { NUMBER OF } \\
\text { STUDIED } \\
\text { OBJECTS }\end{array}$ & $\begin{array}{c}\text { AS A \% OF ALL } \\
\text { STUDIED } \\
\text { OBJECTS }(n= \\
\text { 393) }\end{array}$ & $\begin{array}{c}\text { AS A \% OF ALL } \\
\text { 'PHASED' } \\
\text { STUDIED } \\
\text { OBJECTS }(\boldsymbol{n}= \\
\text { 377) }\end{array}$ & $\begin{array}{c}\text { AS A \% OF } \\
\text { FULLY PHASED } \\
\text { STUDIED } \\
\text { OBJECTS }(n= \\
\text { 158) }\end{array}$ \\
\hline \multirow{7}{*}{ 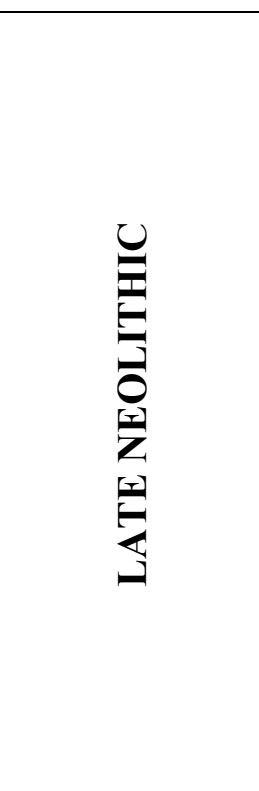 } & $\begin{array}{l}\text { Middle Halaf (c. 5,845- } \\
\text { 5,700) OR Early Halaf (c. } \\
\text { 5,940-5,845) }\end{array}$ & 1 & $0.25 \%$ & $0.27 \%$ & $0.63 \%$ \\
\hline & Early Halaf $(5,940-5,845)$ & 12 & $3.05 \%$ & $3.18 \%$ & $7.59 \%$ \\
\hline & $\begin{array}{l}\text { Transitional (into Halaf, } \\
6,020-5,925 \text { ) }\end{array}$ & 72 & $18.32 \%$ & $19.10 \%$ & $45.57 \%$ \\
\hline & Pre-Halaf $(6,200-6,075)$ & 34 & $8.65 \%$ & $9.02 \%$ & $21.52 \%$ \\
\hline & Early PN $(6,800-6,400)$ & 28 & $7.12 \%$ & $7.43 \%$ & $17.72 \%$ \\
\hline & Initial PN $(6,900-6,800)$ & $\mathbf{1}$ & $0.25 \%$ & $0.27 \%$ & $0.63 \%$ \\
\hline & $\begin{array}{l}\text { Late (ceramic) Neolithic (c. } \\
6,900-5,700) \text { (exact period } \\
\text { uncertain). }\end{array}$ & 219 & $55.73 \%$ & $58.09 \%$ & - \\
\hline \multirow{3}{*}{$\begin{array}{c}\text { EARLY } \\
\text { NEOLITHIC }\end{array}$} & $\begin{array}{l}\text { Early PN }(6,800-6,400) \mathbf{O R} \\
\text { PPNB (c. 7,550-7,000) }\end{array}$ & 1 & $0.25 \%$ & $0.27 \%$ & $0.63 \%$ \\
\hline & PPNB (c. 7,550 - 7,000) & 9 & $2.29 \%$ & $2.39 \%$ & $5.70 \%$ \\
\hline & TOTAL: & 377 & $95.67 \%$ & $99.73 \%$ & $99.37 \%$ \\
\hline
\end{tabular}


Table 8. Comparison of clay object counts (tiers 1-3) across four areas of Tell Sabi Abyad I, considering duration of occupation, extent of village and layout/architecture.

\begin{tabular}{clllc}
\hline OPERATION & LAYOUT & $\begin{array}{c}\text { VILLAGE } \\
\text { SIZE }\end{array}$ & $\begin{array}{c}\text { DURATION } \\
\text { OCF } \\
\text { OCCUPTION }\end{array}$ & $\begin{array}{c}\text { CLAY } \\
\text { OBJECT } \\
\text { COUNT }\end{array}$ \\
\hline I & $\begin{array}{l}\text { Dense } \\
\text { architecture }\end{array}$ & Large & 500 years & 619 \\
II & $\begin{array}{l}\text { Single, large } \\
\text { building. } \\
\text { Dense } \\
\text { architecture }\end{array}$ & Small & c. 200 years & 489 \\
III & $\begin{array}{l}\text { Single, large } \\
\text { building. }\end{array}$ & Small & c. 1,300 years & 583 \\
IV & & & & 4 \\
\hline
\end{tabular}

Table 9. Count and temporal distribution of clay obejcts across the lower and upper phases of occupation in operation II (tier 3 data).

\begin{tabular}{lclcc}
\hline $\begin{array}{l}\text { OCCUPATION } \\
\text { PHASE }\end{array}$ & $\begin{array}{c}\text { DATES } \\
\text { (years cal. BC) }\end{array}$ & PERIOD & $\begin{array}{c}\text { “TOKEN" } \\
\text { COUNT }\end{array}$ & AS A \% \\
\hline Upper & $6,000-5,800$ & Early Halaf & 383 & $78 \%$ \\
Lower & c. $6,050-6,020$ & $\begin{array}{l}\text { Transitional } \\
\text { Halaf }\end{array}$ & 106 & $22 \%$ \\
COMBINED & $/$ & \multicolumn{1}{|c}{} & $\mathbf{4 8 9}$ & $\mathbf{1 0 0 \%}$ \\
\hline
\end{tabular}


Table 10. The distribution of individually studied (tier 1 and 2) clay objects from Tell Sabi Abyad by cultural phase within each excavation area (as published by Akkermans et al. 2014: tables 1.2 p. $26, .3$ p. 28 \& 2.2 p. 31 and amended in Akkermans at al. 2014 : tables $2.1 \& 2.2$ p. 31). All dates are approximate, and in years cal. BC

\begin{tabular}{|c|c|c|c|}
\hline AREA & CULTURAL PHASE & $\begin{array}{l}\text { NUMBER OF } \\
\text { RECORDED } \\
\text { CLAY } \\
\text { OBJECTS }\end{array}$ & $\begin{array}{c}\text { AS A \% OF } \\
\text { ALL } \\
\text { RECORDED } \\
\text { CLAY } \\
\text { OBJECTS } \\
\text { WITHIN } \\
\text { AREA } \\
\end{array}$ \\
\hline Op. I, Tell Sabi & Early Halaf $(5,940-5,845)$ & 12 & $13.95 \%$ \\
\hline \multirow[t]{4}{*}{ Abyad I } & $\begin{array}{l}\text { Transitional (into Halaf) }(6,020- \\
5,925)\end{array}$ & 72 & $83.72 \%$ \\
\hline & Pre-Halaf $(6,200-6,075)$ & 1 & $1.16 \%$ \\
\hline & Early PN $(6,800-6,400)$ & 1 & $1.16 \%$ \\
\hline & AREA TOTAL: & 86 & $100.00 \%$ \\
\hline Op II, Tell Sabi & Pre-Halaf $(6,200-6,075)$ & 4 & $100.00 \%$ \\
\hline Abyad I & AREA TOTAL: & 4 & $100.00 \%$ \\
\hline \multirow[t]{5}{*}{$\begin{array}{l}\text { Op. III, Tell Sabi } \\
\text { Abyad I }\end{array}$} & $\begin{array}{l}\text { Middle Halaf (c. } 5,845-5,700) \text { to } \\
\text { Early Halaf (c. } 5,940-5,845)\end{array}$ & 1 & $0.36 \%$ \\
\hline & Pre-Halaf (c. 6,200-6,075) & 29 & $10.55 \%$ \\
\hline & Early PN (c. 6,800-6,400) & 26 & $9.45 \%$ \\
\hline & $\begin{array}{l}\text { BROAD: Late Neolithic } \\
\text { (ceramic: } 6,900-5,700) \text {, exact } \\
\text { period uncertain }\end{array}$ & 219 & $79.64 \%$ \\
\hline & AREA TOTAL: & 275 & $100.00 \%$ \\
\hline \multirow[t]{3}{*}{ Tell Sabi Abyad II } & $\begin{array}{l}\text { PPNB (c. } 7,550-7,000) \text { OR } \\
\text { Early PN }(6,700-6,300)\end{array}$ & 1 & $10.00 \%$ \\
\hline & PPNB (c. 7,550 - 7,000) & 9 & $90.00 \%$ \\
\hline & AREA TOTAL: & 10 & $100.00 \%$ \\
\hline \multirow[t]{4}{*}{ Tell Sabi Abyad III } & $\begin{array}{l}\text { PPNB (c. } 7,550-7,000) \mathbf{O R} \\
\text { Early PN }(6,700-6,400)\end{array}$ & 1 & $10.00 \%$ \\
\hline & PPNB (c. 7,550 - 7,000) & 9 & $90.00 \%$ \\
\hline & AREA TOTAL: & 2 & $11.11 \%$ \\
\hline & TOTAL: & 377 & - \\
\hline
\end{tabular}


Table 11. The temporal distribution of all likely 'tokens' excavated from operation I, Tell Sabi Abyad I, as recorded in the site archives (tier 3 unpublished data). Total count, $n=619$, number with detailed stratigraphic data available, $n=462(74.64 \%)$. Dates and 'cultural' periods as published in years calibrated BC (Modified from Akkermans et al. 2014 tbl.1.2 p. 26 and tbl. 1.3 p. 28).

\begin{tabular}{|c|c|c|c|c|c|}
\hline $\begin{array}{l}\text { STRATIGRAPHIC } \\
\text { LEVEL }\end{array}$ & CULTURAL PHASE & DATE & $\begin{array}{l}\text { NO. OF } \\
\text { 'TOKENS' }\end{array}$ & $\begin{array}{c}\text { AS A \% OF } \\
\text { ALL EXC. } \\
\text { WITH DATA }\end{array}$ & $\begin{array}{l}\text { AS A \% OF } \\
\text { ALL EXC. }\end{array}$ \\
\hline Level 1 & Early Halaf & $5,900-5,845$ & 6 & $1.30 \%$ & $0.97 \%$ \\
\hline Level 2 & (c. 5845-5940) & $5,920-5,880$ & $\mathbf{0}$ & - & - \\
\hline Level 3 & & $5,940-5,905$ & 1 & $0.22 \%$ & $0.16 \%$ \\
\hline Level 4 & Transitional Halaf & $5,980-5,925$ & 2 & $0.43 \%$ & $0.32 \%$ \\
\hline Level 4/5 & (c. 5980-6020) & - & 3 & $0.65 \%$ & $0.48 \%$ \\
\hline Level 5 & & $6,000-5,945$ & 10 & $2.16 \%$ & $1.62 \%$ \\
\hline Level 5/6 & & - & 2 & $0.43 \%$ & $0.32 \%$ \\
\hline Level 6 & & $6,010-5,995$ & 200 & $43.29 \%$ & $32.31 \%$ \\
\hline Level 6/7 & & - & 47 & $10.17 \%$ & $7.59 \%$ \\
\hline Levels 5/6/7 & & - & 7 & $1.52 \%$ & $1.13 \%$ \\
\hline Level 7 & & $6,020-5,995$ & 61 & $13.20 \%$ & $9.85 \%$ \\
\hline Levels 6/7/8 & Transitional / Pre-Halaf & - & 1 & $0.22 \%$ & $0.16 \%$ \\
\hline Level 7/8 & & - & 8 & $1.73 \%$ & $1.29 \%$ \\
\hline Level 8 & Pre-Halaf (c. 6125-6075) & $6,125-6,075$ & 114 & $24.68 \%$ & $18.42 \%$ \\
\hline Unavailable & & - & 157 & - & $25.36 \%$ \\
\hline TOTAL & & & 462 & $100 \%$ & $74.64 \%$ \\
\hline
\end{tabular}


Table 12. Detail of the context type of all individually studied_(tier 1 and 2) Tell Sabi Abyad geometric clay objects $(n=393$, all tells, levels, operations combined), broadly divided into internal and external context types.

\begin{tabular}{|c|c|c|c|}
\hline LOCATION & NATURE OF CONTEXT & $\begin{array}{c}\text { NO. OF } \\
\text { OBJECTS } \\
\end{array}$ & $\%$ \\
\hline Building (unspecified) & Doorway & 1 & $0.25 \%$ \\
\hline Building (unspecified) & Floor, Room & 1 & $0.25 \%$ \\
\hline Building (unspecified) & Floor? Under room floor? & 1 & $0.25 \%$ \\
\hline Building (unspecified) & Oven & 1 & $0.25 \%$ \\
\hline Building (unspecified) & Room & 15 & $3.82 \%$ \\
\hline Building (unspecified) & Room & 1 & $0.25 \%$ \\
\hline Building (unspecified) & Room & 1 & $0.25 \%$ \\
\hline Building (unspecified) & Room, Wall & 1 & $0.25 \%$ \\
\hline Building (unspecified) & Wall & 3 & $0.76 \%$ \\
\hline Building complex & Courtyard & 1 & $0.25 \%$ \\
\hline Building complex & Oven, Room & 1 & $0.25 \%$ \\
\hline Building complex & Room & 8 & $2.04 \%$ \\
\hline Building complex & Room, wall & 1 & $0.25 \%$ \\
\hline Building-'tholos' & Room & 6 & $1.53 \%$ \\
\hline Building-rectilinear & Room & 69 & $17.56 \%$ \\
\hline Building-tripartite & Room & 2 & $0.51 \%$ \\
\hline Building-T-shaped & Room & 4 & $1.02 \%$ \\
\hline Possible building (any type) & Room & 6 & $1.53 \%$ \\
\hline \multicolumn{2}{|c|}{ TOTAL: INTERNAL SPACES } & 121 & $30.79 \%$ \\
\hline Courtyard & - & 8 & $2.04 \%$ \\
\hline Courtyard & Platform & 2 & $0.51 \%$ \\
\hline Courtyard/Open area & Courtyard & 1 & $0.25 \%$ \\
\hline Courtyard/Open area & Underneath platform/foundation & 2 & $0.51 \%$ \\
\hline Midden/refuse area & - & 1 & $0.25 \%$ \\
\hline Open area & - & 175 & $44.53 \%$ \\
\hline Open area & Courtyard & 28 & $7.12 \%$ \\
\hline Open area & Other (detail in notes) & 1 & $0.25 \%$ \\
\hline Open area & Between Buildings & 1 & $0.25 \%$ \\
\hline Open area & Between Buildings & 1 & $0.25 \%$ \\
\hline Open area & Ditch & 2 & $0.51 \%$ \\
\hline Open area & Other & 1 & $0.25 \%$ \\
\hline Open area & Oven & 11 & $2.80 \%$ \\
\hline Open area & Unclear/not detailed & 3 & $0.76 \%$ \\
\hline Open burial area (entire square) & - & 6 & $1.53 \%$ \\
\hline Open burial area (entire square) & - & 1 & $0.25 \%$ \\
\hline Passage & Between Buildings & 3 & $0.76 \%$ \\
\hline Pit & Other & 1 & $0.25 \%$ \\
\hline Possible/probable Open area & Courtyard & 1 & $0.25 \%$ \\
\hline Possible/probable Open area & - & 2 & $0.51 \%$ \\
\hline Possible/probable Open area & Unclear/not detailed & 1 & $0.25 \%$ \\
\hline Top soil/surface find & - & 1 & $0.25 \%$ \\
\hline \multicolumn{2}{|c|}{ TOTAL: EXTERNAL SPACES } & 254 & $64.63 \%$ \\
\hline Unclear/uncertain & - & 14 & $3.56 \%$ \\
\hline Not published (tier 2) & - & 1 & $0.25 \%$ \\
\hline \multirow[t]{2}{*}{ Not published (tier 2) } & - & 3 & $0.76 \%$ \\
\hline & TOTAL & 393 & $100.00 \%$ \\
\hline
\end{tabular}


Table 13. Table detailing of the number and distribution of small geometric clay objects ('tokens') and other common clay artefact types within the lower phase T-shaped burnt building, operation II. Room 8 contained the female burial (Data from Tell Sabi Abyad Research Project archives).

\begin{tabular}{|c|c|c|c|c|c|c|c|c|c|c|}
\hline $\begin{array}{c}\text { ROOM: T- } \\
\text { SHAPED } \\
\text { BLD. }\end{array}$ & BURNT? & 'TOKEN' & 'BULLA' & 'FIGURINE' & 'LABRET' & $\begin{array}{c}\text { PIERCED / } \\
\text { POT- } \\
\text { SHERD } \\
\text { DISC } \\
\end{array}$ & $\begin{array}{c}\text { 'SEALING/JAR } \\
\text { STOPPER' }\end{array}$ & $\begin{array}{c}\text { 'SLING } \\
\text { MISSILE' }\end{array}$ & $\begin{array}{c}\text { POTTERY } \\
\text { SHERDS }\end{array}$ & TOTAL \\
\hline Room 1 & Heavily & 20 & 0 & 2 & 1 & 23 & 19 & 6 & 671 & 742 \\
\hline Room 2 & Heavily & 0 & 0 & 0 & 1 & 3 & 0 & 1 & 79 & 84 \\
\hline Room 3 & Heavily & 42 & 3 & 1 & 0 & 3 & 21 & 8 & 46 & 124 \\
\hline Room 4 & No & 15 & 0 & 0 & 0 & 1 & 0 & 1 & 93 & 110 \\
\hline Room 5 & Heavily & 13 & 1 & 1 & 1 & 9 & 35 & 1 & 672 & 733 \\
\hline Room 6 & Partially & 0 & 0 & 0 & 2 & 3 & 0 & 0 & 112 & 117 \\
\hline Room 7 & Partially & 0 & 0 & 0 & 0 & 0 & 0 & 0 & 108 & 108 \\
\hline Room 8 & No & 0 & 0 & 0 & 0 & 1 & 0 & 1 & 31 & 33 \\
\hline TOTAL: & & 90 & 4 & 4 & 5 & 43 & 76 & 18 & 1812 & 2052 \\
\hline
\end{tabular}

